\title{
Reconstructing Sexual Equality
}

\author{
Christine A. Littleton $\dagger$
}

Feminist theorists have critiqued both legal equality doctrine and society's power structure as "phallocentric"-that is, reflecting solely the perspective of men. These critiques have fostered two conflicting visions of sexual equality: the "equal treatment" or "symmetrical" model, and the "special treatment" or "asymmetrical" model. After surveying the spectrum of current equality theory, Professor Littleton proposes her own model of sexual equality, called "equality as acceptance," which she identifies as essentially asymmetrical. She then demonstrates how her "acceptance" model responds to the feminist critiques of equality and power. Professor Littleton argues that women's biological and cultural differences from men, regardless of whether they are "natural" or constructed, are real and signiflcant. Women's inequality, she contends, results when society devalues women because they differ from the male norm. "Acceptance" would reduce inequality not by eliminating women's differences, but by reassessing the value society accords to traditionally "female" occupations and lifestyles, and revaluing so as to render such value no less than that accorded to equivalent "male" activities.

\section{Introduction: The Project}

Like and different are quickening words, brooding and hatching.

Better and worse are eggsucking words, they leave only the shell.

-Ursula K. LeGuin ${ }^{1}$

Feminist critique has illuminated the "male-dominated" or "phallocentric"2 nature of every social institution it has examined, including

$\dagger$ Acting Professor of Law, University of California, Los Angeles. B.S. 1974, Pennsylvania State University; J.D. 1982, Harvard Law School.

This Article has benefited from an enormous number of people and organizations. Research funding was provided by the University of California Academic Senate and the Institute of Industrial Relations at UCLA. In addition to general research assistance from Annette DeMichele and Steven Susoeff, I have been fortunate to have had the unusually thorough and able help of Jane Newman. The ideas were developed through presentations of various papers to the Feminist Critical Legal Studies Conference, both the West and the East Coast Feminist Critical Legal Scholars, and the UCLA Faculty Research Seminar on Women, all of whose members provided helpful criticism and support. Of the many colleagues and friends who read endless drafts, the following deserve special thanks: Richard Abel, Alison Anderson, Grace Blumberg, Jon Davidson, Herma Hill Kay, Kenneth Karst, Sheila McIntyre, Carrie Menkel-Meadow, and Sylvia Walby.

1. U.K. LeGuin, Always Coming Home 313 (1985).

2. "Male-dominated" and "male-biased" are the terms usually used by feminists writing 
law. ${ }^{3}$ Critiques of the patriarchal family are by now too familiar to need recounting, and the feminist project has moved on. Feminists have revealed religion as a cultural artifact of the patriarchal conquest of female power; ${ }^{4}$ the sciences as "intimately involved in Western, bourgeois, and masculine projects;" 5 and even law as the symbol and mechanism for continuation of male power. ${ }^{6}$ Much of the critique has focused on women's absence from, or at least marginal place in, the discourse and thought that has shaped modern social structures.

Although one more criticism of men's domination of the public discourse on equality might not be amiss, that is not the focus of this Article. ${ }^{7}$ Rather, the focus here is on a more insidious and complex form of male domination, which I term "phallocentrism." A history of almost exclusive male occupation of dominant cultural discourse has left us with more than incompleteness and bias. It has also created a self-referencing system by which those things culturally identified as "male" are more highly valued than those identified as "female," even when they appear to have little or nothing to do with either biological sex. By this process, "to be a man" does not simply mean to possess biologically male traits, but also to take on, or at least aspire to, the culturally male. ${ }^{8}$ Similarly,

within the liberal legal tradition. Such terminology is, however, too easily read as implying that "gender-neutral" institutions will result if we merely "add women and stir" or "squeeze the male tilt out" of the institution. See, e.g., Williams, Equality's Riddle: Pregnancy and the Equal Treatment/ Special Treatment Debate, 13 N.Y.U. Rev. L. \& Soc. Change 325, 331 (1985) [hereinafter Williams, Equality's Riddlel (disparate impact analysis under Title VII will "squeeze the male tilt out" of employment practices). My analysis leads me to concludc that actually squeezing out the male tilt of any social institution would not leave much of the institution.

Alternatively, radical feminist theory often refers to social institutions as simply "male." While this term captures more of the genderedness of social institutions, it too easily confuses biological sex with social sex when used to refer to both.

"Phallocentric" or "phallologocentric" are terms coined by the French feminists of the "politique et psychoanalyse" school, which tends to view social institutions as created from the male viewpoint-i.e., as epistemologically "male." See NEw FrenCH FEMINISMS: AN ANTHOLOGY 5, 36 (E. Marks \& I. de Courtivron eds. 1980) [hereinafter FrENCH FEMINISMS]; L. IRIGARAY, THIS SEX WHICH Is NOT ONE 163 (C. Porter trans. 1985) ("Isn't the phallic tantamount to the seriousness of meaning?") (emphasis deleted). I adopt the term "phallocentric" as closest to describing the full content of feminist critique as I read it. See infra text accompanying notes 8-9.

3. See, e.g., Polan, Toward a Theory of Law and Patriarchy, in THE PoLitics of LAw 294, 297-300 (D. Kairys ed. 1982) (analyzing how law perpetuates patriarchy); Rifkin, Toward a Theory of Law and Patriarchy, 3 HARV. WOMEN's L.J. 83, 83-85 (1980) (analyzing how law blocks social change for women).

4. See M. Stone, When God Was A Woman (1976).

5. See S. HARding, The SCience Question in Feminism 9 (1986).

6. Rifkin, supra note 3 , at 95 .

7. In fact, the emergence of a significant number of female legal scholars, and their development of a new field of inquiry known as "feminist jurisprudence," makes this Article possible. Rather than drawing primarily on male equality theorists, I have the luxury (and perhaps the duty) to draw primarily on feminist legal thought.

8. Because the links between biological and cultural sex are so tenuous, it is possible for individuals to engage in cultural "cross-dressing," thus complicating any analysis (such as legal analysis of sex discrimination) that depends on clear identification of "immutable characteristics." 
social institutions within a male-dominated culture can be identified as "male" in the sense that they are constructed from the perspective of the culturally male. By use of the term "phallocentrism" I hope to capture this perspective-not the perspective of biological males, but the perspective to which the culture urges them to aspire, and by which the culture justifies their dominance. ${ }^{9}$

Language, being a social institution-perhaps even the constitutive social institution ${ }^{10}$-is also subject to feminist critique. While Carol Gilligan's In a Different Voice does not deal explicitly with language, it is aptly titled. ${ }^{11}$ In uncovering the limitations of Kohlberg's theory of moral development, Gilligan discovered more than the methodological error of constructing a theory of human reasoning from a sample of only male humans. ${ }^{12}$ She also uncovered a "different voice," one that reasons morally in terms of connection and relationship, rather than in terms of separation, hierarchy of values, and abstraction of principles. While this voice was exhibited by more female children than male children, it was by no means limited to one biological sex. ${ }^{13}$

The "French feminists"14 attack language more explicitly, finding in the disruption of male language the only possible expression of a female voice. ${ }^{15}$ Whether the problem identified by feminists is as "simple" as

9. Leaving behind much of its biological referent, the "phallus" has come to have social meaning that removes it from the realm of the signifier into the realm of the signified.

10. See, e.g., D. SPENDER, MAN-MADE LANGUAGE 3 (2d ed. 1985) ("Language helps form the limits of our reality. It is our means of ordering, classifying and manipulating the world. It is through language that we become members of a human community, that the world becomes comprehensible and meaningful, that we bring into existence the world in which we live.").

11. C. Gilligan, in a Different Voice (1982).

12. Id. at 18. Kohlberg's theory identified six different stages of human moral reasoning from childhood to adulthood. The theory was based on an empirical survey of 84 boys whose development Kohlberg studied for more than 20 years.

13. Id. at 25. This voice of caring and connection was often "unheard" by researchers who, bound by Kohlberg's typology, tried to type the subjects' responses along a developmental continuum that had no place (or only a devalued place) for this voice. Id. at 28-31. Not surprisingly, as adults these "cultural women" learned to speak the language of separation, the one that was valued. See Menkel-Meadow, Portia in a Different Voice: Speculating on a Woman's Lawyering Process, 1 BeRKeley WOMEN's L.J. 39, 42 11.22 (1985). However, whether such people "lose" their native tongue or simply become bilingual is unclear. See DuBois, Dunlap, Gilligan, MacKinnon \& Menkel-Meadow, Feminist Discourse, Moral Values, and the Law-A Conversation, 34 Buffalo L. Rev. 11, 40-41 (1985) [hereinafter Feminist Discourse].

14. See generally French Feminisms, supra note 2.

15. See Gauthier, Is There Such a Thing as Women's Writing?, in FRENCH FEMINISMS, supra note 2, at 161-64.

And then, blank pages, gaps, borders, spaces and silence, holes in discourse: these women emphasize the aspect of feminine writing which is the most difficult to verbalize because it becomes compromised, rationalized, masculinized as it explains itself.... If the reader feels a bit disoriented in this new space, one which is obscure and silent, it proves perhaps, that it is women's space.

Id. at 164 . 
the use of the generic "he,"16 or as complex as the structure of language itself, the reach of feminist critique is toward the phallocentric construction of the medium by which we transmit knowledge, rather than merely toward the sexist word choice of individuals. In all its manifestations, phallocentrism defines the boundaries of acceptable discourse-not only of what can be heard and responded to, but also to some extent of what can be thought, ${ }^{17}$ and thus the extent to which women can articulate their own concerns, values, and interests.

Equality, belonging both to law and to language, provides its own case study of phallocentrism. Using feminist methodology's primary questions-"What has been women's concrete experience?" and "What has been left out?" 18 - feminist critique has examined the phallocentrism of equality as both a concept and a form of legal analysis. As a concept, equality suffers from a "mathematical fallacy"-that is, the view that only things that are the same can ever be equal. ${ }^{19}$ In legal analysis, courts routinely find women's "difference" a sufficient justification for inequality, constructing at the same time a specious "sameness" when applying phallocentric standards "equally" to men and women's different reproductive biology or economic position to yield (not surprisingly) unequal results for women..$^{20}$

This feminist critique of equality has cast doubt on the merits of another feminist enterprise- the as yet only partially successful attempt by feminist lawyers to have sex accepted as similar to, and coextensive with, race under constitutional and statutory guarantees of equality. ${ }^{21}$ "Equality," which has historically been the rallying cry of every subordinated group in American society, can no longer be embraced

16. See State v. Wanrow, 88 Wash. 2d 221, 240-41, 559 P.2d 548, 558-59 (1977) ("persistent use of the masculine gender" in jury instructions on self-defense disadvantaged female defendant).

17. George Orwell describes a form of this phenomenon in his disutopian novel 1984, in which the government seeks to control thought by limiting language. See G. ORWELL, 1984 (1949).

18. See, e.g., C. Gilligan, supra note 11, at 5-23; Wishik, To Question Everything: The Inquiries of Feminist Jurisprudence, 1 BERKELEY WOMEN's L.J. 64, 72-73 (1985).

19. See infra text accompanying notes 166-67. In noting the overt and covert forms of discrimination that make boys more interested than girls in excelling at the sciences, Sandra Harding asks, "should women want to become 'just like men' in science . . . ? That is, should feminism set such a low goal as mere equality with men?" S. HARDiNG, supra note 5, at 21.

20. See infra Part II.

21. While racial classifications are subjected to "strict scrutiny," and struck down unless necessary to accomplish a compelling governmental interest, see Regents of the Univ. of Cal. v. Bakke, 438 U.S. 265, 289-91 (1978), sex classifications are subjected to an intermediate level of scrutiny. Although the test is still under debate, there is some consensus on the Court that sex classifications need only be substantially related to an important governmental interest. See Craig v. Boren, 429 U.S. 190, 197 (1976). In traditional fourteenth amendment jurisprudence, it is not inequality but the presence of a racial or sexual classification that triggers equality analysis. This focus on classification rather than conditions renders the equal protection clause far more significant in symbolic terms than in practical ones. 
unambivalently by feminists. ${ }^{22}$

Equality is enmeshed in, and ensnared by, the very gender system feminists are resisting. But I believe it is capable of having meaning beyond that system. To the extent that it is a social construct, ${ }^{23}$ equality can be deconstructed and, at least theoretically, reconstructed as a means of challenging, rather than legitimating, social institutions created from the phallocentric perspective. ${ }^{24}$ This possibility is so appealing, so evocative of the yearnings of so many of us, ${ }^{25}$ that the project of reconstructing sexual equality ${ }^{26}$ must at least be attempted, difficult and fraught with

22. "Men are set up as a standard for women by saying either: "You can be the same as men, and then you will be equal,' or 'You can be different from men, and then you will be women." Feminist Discourse, supra note 13 , at 21.

The identification of nonassimilation with inequality is not a new phenomenon. Witness, for example, the early 20th century feminist debates personified by Florence Kelly and Alice Paul, recently reexamined by Katharine Sklar. Sklar, Hull House in the 1890s: A Community of Women Reformers, 10 Sians 658 (1985).

23. I take this question to be broader than whether equality is a construct of unequal power, as Catharine MacKinnon claims. See Feminist Discourse, supra note 13, at 27; MacKinnon, Feminism, Marxism, Method and the State: An Agenda for Theory, 7 Signs 515, 542 (1982) [hereinafter MacKinnon, An Agenda For Theory].

24. "Deconstruction" in Critical Legal Studies circles denotes a method of analyzing legal materials. Using the internal contradictions within legal texts and between the texts and their referents, the analyst can demonstrate either intellectual incoherence, see, e.g., Dalton, An Essay in the Deconstruction of Contract Doctrine, 94 YALE L.J. 997 (1985) (discussing indeterminacy of contract rules), or political bias, see, e.g., Klare, Judicial Deradicalization of the Wagner Act and the Origins of Modern Legal Consciousness, 1937-1941, 62 MINN. L. REV. 265 (1978) (discussing the judicial impact upon organized labor and its consequences). For a cogent critique of Critical Legal Studies' use of deconstruction, see Brosnan, Serious But Not Critical, 60 S. CAL. L. REv. 259, 374-88 (1987).

Some CLS scholars avoid attempts to move beyond deconstruction into reconstruction because of the danger of incorporating pre-critical elements. This caution is not without reason. See, e.g., Peller, The Politics of Reconstruction (Book Review), 98 HARV. L. REV. 863 (1985) (reviewing B. ACKERMAN, RECONSTRUCTING AMERICAN LAW (1984)) (criticizing Ackerman's recapitulation of conservative ideology). Yet reconstruction is crucial for less powerful groups such as women and Blacks, who are not in a position to abandon hard-won rights for the ephemeral promise of direct political struggle. See, e.g., Crenshaw, Race, Reform, and Retrenchment (forthcoming in volume 101 of the Harvard Law Review) (advocating civil rights struggle that avoids demobilizing effects of abstract rights rhetoric by rooting such struggle in the concrete experience of Blacks).

25. Keeping in mind the crucial question asked by the French feminists, "Who is speaking?" I have attempted to be as clear as possible in this essay about who "I" am and who "we" are. I speak as a feminist, a woman, a white person, a legal academic, and a member (though perhaps not a full one) of American society. While I agree that feminism does, and must, set itself the task of speaking from the viewpoint of all women, see An Agenda For Theory, supra note 23, at $520 \mathrm{n} .7$ ("I aspire to include all women in the term 'woman' in some way, without violating the particularity of any woman's experience."), I realize that I fall short of that goal on numerous occasions. I must nevertheless speak with whatever voice I can muster.

26. I use the term "sexual equality" for several reasons, some of which are based on the simple desire to escape from the limitations of alteruative terminology. "Sex discrimination," the most common reference in legal materials, is far too restrictive, in ways that I have previously criticized. See Note, Toward a Redefinition of Sexual Equality, 95 HARv. L. Rev. 487 (1981). Discrimination is not the only way in which inequality is created or maintained.

The choice of "sex" rather than "gender" is more problematic, especially since much of this Article focuses on the cultural significance of sex, a phenomenon for which many feminists use the 
dangers as it appears. ${ }^{27}$ Even if we disregard the pragmatic value of equality analysis as one of the few avenues by which concrete experiences of subordination can be translated into legal claims, ${ }^{28}$ we should not disregard the relational nature of equality language, ${ }^{29}$ its consistent theme of belonging, ${ }^{30}$ of somehow "counting" as human.

This Article attempts a speculative reconstruction of sexual equality $^{31}$ that I find appealing. My hope is that others-especially feininists and feminist sympathizers - will find it appealing too. My proposal is easy to state, somewhat harder to fill with content, and even harder to implement. It is simply this: The difference between human beings, whether perceived or real, and whether biologically or socially based, should not be permitted to make a difference in the lived-out equality of

term "gender." See, e.g., S. HARDING, supra note 5, at 15 n.1. However, the relationship between sex and gender does not seem so clear-cut to me. See infra, Part II. In addition, using "gender" often masks the way in which sexual inequality works against women rather than against men. Many female Women's Studies scholars have expressed concern over the transformation of their field into "gender studies" and the concomitant addition of "men's studies" courses into the curriculum; I am loath to add aid or comfort to any notion that men and women suffer equally from sexual inequality. See infra, Part III; see also Wildman, The Legitimation of Sex Discrimination: A Critical Response to Supreme Court Jurisprudence, 63 OR. L. REv. 265, 304-05 (1984) ("Women, not men, are the victims of sex discrimination ....").

Finally, I use "sexual" rather than "sex" to indicate the possible connection between women's legal, social, and sexual status. While I am not convinced, as a significant portion of the radical feminist community appears to be, that the realm of sexuality is the "linchpin" of women's inequality, I do not think that realm is irrelevant, as some socialist-feminist analysis might lead one to conclude. Rather, I view the sex/gender system (that is, the process of ascribing cultural significance to biological sex), economic disadvantage, and sexual subordination as linked in a nonhierarchical fashion. I use the term "sexual equality" in an attempt to hold together all of these notions, without sacrificing one to any other.

27. See Williams, The Equality Crisis: Some Reflections on Culture, Courts and Feminism, 7 WOMEN'S RTS. L. REP. 175, 198-200 (1982) [hereinafter Williams, The Equality Crisis] (discussing dangers of seeing women as different from men).

28. The transformation of sexual harassment from an unmentioned and unmentionable problem of working women into a legal claim of sex discrimination is the clearest example. See MacKinnon, Introduction to Symposium: Sexual Harassment, 10 CAP. U.L. REV. i, i-ii (198I); see also L. Farley, Sexual Shakedown: The Sexual Harassment of Women on the Job (1978); D. Russell, Sexual Exploitation $269-81$ (1984); $c f$. B. Dziech \& L. Weiner, The LECherous Professor (1984) (detailing the sexual harassment of college students by professors). See generally C. MacKinnon, Sexual HaRAsSMENT of WORKING WOMEN (1979) (detailing the theory and practice of transforming sexual harassment into a legal cause of action).

29. That equality discourse is comparative is not controversial; that it is relational may be. Though feminists have criticized equality discourse as employing the kind of comparative thinking that leads to competition rather than cooperation, traditional equality discourse can speak of a commonality among human beings, though its users have often mistaken one part of humanity for the whole.

30. Karst, Why Equality Matters, 17 GA. L. REv. 245, 248-49 (1983) ("For it is precisely the denial of equal status, the treatment of someone as an inferior, that causes stigmatic harm . . . . Stigma dissolves the human ties we call 'acceptance' and excludes the stigmatized from 'belonging' as equais.").

31. I believe that this particular reconstruction may have relevance to other bases of inequality, but here I confine my speculations to the situation of women vis-a-vis men. 
those persons. I call this the model of "equality as acceptance."32 To achieve this form of sexual equality, male and female "differences" must be costless relative to each other. Equal acceptance cannot be achieved by forcing women (or the rare man) individually to bear the costs of culturally female behavior, such as childrearing, while leaving those (mostly men and some women) who engage in culturally male behavior, such as private law firm practice, to reap its rewards. ${ }^{33}$

Part I of this Article describes the legal system's response to the civil rights movement of the 1950's and 1960's. ${ }^{34}$ It then describes femimist legal scholars' reaction to, and attempts to use, the tools of equality analysis thus forged. In so doing, it locates the model of equal acceptance within the still developing field of feminist legal scholarship on equality.

Part II elaborates the feminist critique of equality as phallocentric. The primary thrust of that critique is twofold. First, equality analysis, as currently practiced, presupposes a degree of similarity between the sexes that is simply untenable in a society im which they have been constructed so differently. Second, by treating difference solely from the male perspective, equality analysis entirely fails to address women's experience of being treated as man's "other."35

Part III explores the relationship between the inability of equality analysis to deal with difference and the constitution of male power as a system. It concludes that to the extent phallocentrism demands conformity to male modes of behavior as a prerequisite of "equality," a model of sexual equality that calls for acceptance of gender difference will be subversive to the system of male power. ${ }^{36}$

32. The model of equality as acceptance has a fairly specific content that distinguishes the term "acceptance" from its use by other equality theorists such as Kenneth Karst. See Karst, Foreword: Equal Citizenship Under the Fourteenth Amendment, 91 HARv. L. REv. 1 (1977). In Karst's model of "equal citizenship," acceptance means only the absence of stigma. Leaving in place current hierarchies of value, Karst argues for the equal right of all citizens to aspire to whatever is socially valued. In contrast, the model of acceptance that I propose challenges those value hierarchies. It asserts that women have not simply been excluded from the "good life," but our potential contribution to the definition of that good life has also been ignored. See infra Part III.

33. Whether the costs and rewards should be shared by private arrangement or spread by public arrangement depends on a number of factors, including the particular pattern of costs or rewards to be equalized, the availability and scope of legal tools, and the prevailing political and social climate. A thorough examination of this question will therefore have to await a later article.

34. Some of this ground I have previously tilled. See Note, supra note 26, at 499-508; see also Karst, supra note 32, at 21 (footnotes omitted):

The critical event was the decision in Brown v. Board of Education. Brown is now much more than a schools case, or even a desegregation case. It stands as our leading authoritative declaration that the Constitution forbids a system of caste. The significance of this precept is not limited to issues of racial equality; when Brown sparked the modern civil rights movement, it also set in motion forces (moral and political) that fostered other "liberation" movements.

35. See S. DE Beauvoir, The Second SEX 57 (H. Parshley trans. 1952).

36. Feminists are not the only group that has sought to use equality doctrine in a subversive manner. See, e.g., Unger, The Critical Legal Studies Movement, 96 HARv. L. Rev. 563, 602-18 
Part IV explores some ramifications of the "equality as acceptance" model as applied to a range of currently conceptualized sexual differences. It also describes some difficulties that attend this project on the level of social theory, and offers some tentative resolutions of them. ${ }^{37}$ It concludes with a call for further research on uncovering the dichotomized axes by which the culture differentiates male and female.

The parts of this Article reflect the development of the model of sexual equality as acceptance. The model responds to four separate but interrelated ideas: (1) intellectual development of equality analysis in general, and feminist equality analysis in particular; (2) feminist critique of equality; (3) feminist critique of male power as a system; and (4) the complexity of various sex or gender differences. The Article's scope is constrained in a number of ways, not the least of which is my use of "the master's tools" 38 in attempting to reconstruct sexual equality. Recognizing these constraints, I accept the task of building theory on the tightrope between incrementalism and utopianism. ${ }^{39}$

We have inherited the forms and content of equality from our fathers, who occupied the available space in the public discourse. Perhaps we can pass on something richer to our daughters.

I

\section{Development of Feminist Legal Theory}

This Part attempts to locate the model of equality as acceptance within the body of feminist legal theory by tracing the intellectual development of that body. It devotes particular attention to the current form of the long-standing debate between the "equal treatment" and "special

(1983) ("blacks and certain other ethnic groups ... [arel segments of the population that generalitycorrecting equal protection is mainly designed to protect").

37. Various aspects of the reconstruction project, especially questions of implementation, are left for future articles. See Littleton, Equality Across Difference: Is There Room for Rights Discourse? 3 Wis. WoMEN's L.J. 189 (1987) [hereinafter Littleton, Equality Across Difference] (exploring how rights analysis might differ under a model of equal acceptance); Littleton, Reconstructing the Workplace: The Potential and Limitations of Title VII (article in progress) (on the implementation of equal acceptance in employment); Littleton, Integration, Segregation and Separatism: Strategies for Change (article in progress) (program of social change building on the construction of a womancentered perspective).

38. A. LORDE, The Master's Tools Will Never Dismantle the Master's House. in SiSTER Outsider 110 (1984) (comments at "The Personal and the Political Panel," Second Sex Conference, New York, September 29, 1979). Lorde's compelling critique of academic feminism's failure to address difference among women both underscores the importance of finding a way to make equality applicable across difference, id. at 111 ("Difference must be not merely tolerated, but seen as a fund of necessary polarities between which our creativity can spark like a dialectic."), and warns that my own argument may be too narrow, see id. at 110-11 ("What does it mean when the tools of a racist patriarchy are used to examine the fruits of that same patriarchy? It means that only the most narrow perimeters of change are possible and allowable.").

39. See Unger, supra note 36 . 
treatment" branches of feminist equality analysis. ${ }^{40}$ Too often, these extremes have tended to become polarized while the rest of the spectrum has disappeared. While describing these poles, I will also try to fill in some of the missing spectrum.

In most social debates, the participants inevitably desire to obtain a rhetorical advantage from the characterization of their positions. (Consider, for example, the mileage that the term "pro-life" has given the antiabortion movement.) Feminist legal scholars have not been immune to this impulse. For example, "equal treatment" proponents make much of the word "equal," even referring to that view as "the equality approach." 11 Not only does this semantic pushing and shoving make it harder to think clearly about the issues raised by the equality debate, it also places the focus on how "women" should be treated rather than on the more fundamental question of whether and how the existence of two sexes should shape law and society. In the interest of mitigating these problems, I use the terms "symmetry" and "asymmetry" to describe the two directions in feminist legal thought so inaptly identified as "equal treatment" and "special treatment." 42

\section{A. Legal Equality}

Legal concern with sexual equality is very recent. ${ }^{43}$ It developed primarily in response to powerful analogies between the situation of racial minorities, especially Blacks as a class, ${ }^{44}$ and the situation of

40. Wendy Williams and Linda Krieger are probably the best known participants in this debate. For an excellent description of the "equal treatment" position, see Williams, Equality's Riddle, supra note 2. For the other side, so inaptly termed "special treatment," see Krieger \& Cooney, The Miller-Wohl Controversy: Equal Treatment, Pasitive Action and the Meaning of Women's Equality, 13 GoLDEN GATE U.L. REV. 513 (1983); Scales, Towards a Feminist Jurisprudence, 56 IND. L.J. 375 (1981). My earlier work, Note, supra note 26, has usually been classed with the latter, although not always. See Olsen, The Sex of Law (1984) (unpublished manuscript on file with the author) (classifying Williams and myself as legal reformists). For a discussion of how the debate emerges among feminists within the Critical Legal Studies movement, see Menkel-Meadow, Feminist Theory, Critical Legal Studies and Legal Education: "The Fem-Crits Go to Law School" (1988) (forthcoming in volume 38 of the Journal of Legal Education).

41. See, e.g., Williams, The Equality Crisis, supra note 27, at 196 (emphasis added). I, in turn, have sometimes referred to my own position as "treatment as an equal." This terminology was borrowed from Ronald Dworkin. See R. Dworkin, Taking Rights SeriousLy 227 (1977) ("right to treatment as an equal is fundamental, [while] the right to equal treatment [is] derivative"). However, the content of equal acceptance differs from that of Dworkin's treatment as an equal.

42. At the Feminist Legal Theory Symposium at Stanford University in November, 1985, Professor Wendy Williams of Georgetown University Law Center and I shared the podium to discuss the divergent tendencies in feminist legal theory. I proposed, and she graciously adopted, the terminology of "symmetry" and "asymmetry."

43. See, e.g., Reed v. Reed, 404 U.S. 71 (1971); Frontiero v. Richardson, 411 U.S. 677 (1973); Craig v. Boren, 429 U.S. 190 (1976).

44. The convention of capitalizing "Black" when it refers to a people rather than simply to a color, even though perhaps not yet widely accepted, should require little explanation. See, e.g., MacKinnon, An Agenda for Theory, supra note 23, at 516. 
women. ${ }^{45}$ Those analogies were and are highly problematic, both theoretically and historically, ${ }^{46}$ but they supported the claim that women must necessarily be included within the equality-of-persons norm embedded in the political and social framework of this society, and specifically articulated in the equal protection clause of the fourteenth amendment. ${ }^{47}$

Although enacted with the specific situation of Black people ${ }^{48}-$ actually of Black men ${ }^{49}$-in mind, the equal protection clause meant very little to its purported beneficiaries until the notion of "separate spheres" was jettisoned. The paradigm example of separate spheres in the racial context is the 1896 decision of Plessy v. Ferguson, ${ }^{50}$ where the Supreme Court upheld a state statute requiring segregation of Blacks and whites on railroad carriages. This notion was expressed in the opinion as "separate but equal"; theoretically at least, segregation was unsupportable where the facilities were not the same. However, this theoretical point did not gain practical significance until 1950, when, in Sweatt $v$. Painter, ${ }^{51}$ the Supreme Court ordered a Black student admitted to an allwhite law school on the ground that the Black law schools offered by the state did not have similar facilities. ${ }^{52}$

The idea that Blacks and whites "naturally" inhabited separate social spheres was finally rejected in 1954 in the justly famous case of Brown v. Board of Education. ${ }^{53}$ However controversial the various means of implementing that decision have been, ${ }^{54}$ its underlying rejection

45. See generally W. ChAFE, WomeN AND EQuALITY (1977) (especially Chapters 3 and 4, discussing the analogy between racial and sexual equality); Karst, supra note 32.

46. Analogies between the situation of Blacks and the situation of women often mask the ways in which racism operates within sex classes, and sexism operates within racial classes. For example, comparisons of Black slaves to white middle-class women trivialized the conditions of slavery (in terms of economic deprivation and physical violence) and mischaracterized the conditions of middleclass marriage (in terms of sexual subordination). See, e.g., B. Hooks, Ain't I A WOMAN 141.43 (1981); A. Davis, Women, Race \& Class 76-79 (1981).

47. "[N]or shall any State ... deny to any person within its jurisdiction the equal protection of the laws." U.S. CONST. amend. XIV, §1.

48. See Karst, supra note 32, at 13-38; Karst, supra note 30, at 270-71.

49. Some feminist historians have observed that the people most affected by the unfortunate confict between Black suffrage and female suffrage-Black women-were consistently ignored by both abolitionists and white female suffragists. See, e.g.. A. DAvis, supra note 46, at 57.64; sec also P. GIDDINGS, WHEN AND WHERE I ENTER 119-31 (1984).

50. 163 U.S. 537 (1896).

51. 339 U.S. 629 (1950).

52. Of course, the situation never arose in which the Black facilities were better than the white facilities, so that the Court was never faced with the question of whether "separate but equal" meant "separate but similar" or "separate but not worse." But see Wasserstrom, Racism. Sexism and Preferential Treatment: An Approach to the Topics, 24 UCLA. L. REv. 581, 600 (1977) (suggesting that Brown v. Board of Education may have been motivated by the tacit recognition that Black schools were almost always inferior).

53. 347 U.S. 483 (1954).

54. See, e.g., J.A. LuKaS, Common Ground (1985) (describing school desegregation in Boston from the perspectives of several different participants). 
of separate spheres in the racial context remains surprisingly resilient. ${ }^{55}$ At the core of that rejection is the powerful notion that Black men are fundamentally the same as white men, ${ }^{56}$ and that it is irrational for such surface differences of skin color and physiognomy to carry any significant meaning, except perhaps an esthetic one (similar to, say, eye color or foot size). ${ }^{57}$

The consistent message of racial equality analysis since Brown is that any disadvantages Black men face in participating equally with white men in this society are traceable to either irrational prejudice or socially imposed burdens growing out of previous prejudice. In other words, they face no natural handicaps and possess no natural significant differences. ${ }^{58}$ Whether in fact this message has had a sufficient impact on the conditions of Black life in America is open to question, ${ }^{59}$ especially given the Supreme Court's unwillingness to match remedies to its brave ideals. ${ }^{60}$ Nevertheless, this message's significance for the legal recognition of other equality-based claims is indisputable. ${ }^{61}$

55. Perhaps too resilient. An integrationist strategy has failed to provide for the preconditions of effective integration. See Freeman, Legitimizing Racial Discrimination Through Antidiscrimination Law: A Critical Review of Supreme Court Doctrine, 62 MiNN. L. REv. 1049, 1052-57 (1978); see also Bell, Foreword: The Civil Rights Chronicles, 99 HARv. L. REv. 1 (1985) (critiquing the failed promises of equal opportunity and true integration through a series of chronicles related by the character Geneva, and ensuing colloquies between himself and the character). Integration has also frequently meant dilution of whatever power Blacks have managed to achieve through solidarity. See Williams v. New Orleans S.S. Ass'n, 466 F. Supp. 662 (E.D. La. 1979) (white and Black unions ordered integrated despite protests by Black union members that integration would deprive Blacks of leadership roles in the union, as well as reduce the number of union jobs filled by Black workers), aff'd in part and rev'd in part, 673 F.2d 742 (5th Cir. 1982), cert. denied, 460 U.S. 1038 (1983).

56. Cf. Johnston \& Knapp, Sex Discrimination by Law: A Study in Judicial Perspective, 46 N.Y.U. L. REv. 675, 743-44 (1971) (contrasting ability of white male judges to empathize with Black male plaintiffs in discrimination cases with inability of same judges to imagine life as a female). Sometimes the notion embodies an unwillingness to acknowledge difference in circumstance as well. See, e.g., Wechsler, Toward Neutral Principles of Constitutional Law, 73 HARv. L. REv. 1, 34 (1959) ("In the days when I was joined with Charles $H$. Houston in a litigation in the Supreme Court, before the present building was constructed, he did not suffer more than I in knowing that we had to go to Union Station [an integrated lunchroom] to lunch together during the recess.").

57. See Wasserstrom, supra note 52, at 586.

58. See, e.g., T. SOWELl, CiviL RIGHTS: RHEToRIC OR REALitY? 37-60 (1984) (arguing against affirmative action on the basis of cultural rather than racial difference); $c f$. Crenshaw, supra note 24 (critiquing Sowell as simply replacing arguments of racial inferiority with equally offensive arguments of cultural inferiority).

59. Freeman, supra note 55, at 1049-52 (contrasting legal promises with concrete conditions).

60. See Goldstein, A Swann Song for Remedies: Equitable Relief in the Burger Court, 13 Harv. C.R.-C.L. L. REV. 1 (1978) (chronicling barriers to actual progress in school integration).

61. The working out of this message is the judicial development of the disparate impact doctrine under Title VII. Title VII of the Civil Rights Act of 1964, as amended, prohibits employers with 15 or more employees from discriminating on the basis of race, ethnicity, sex, or religion. 42 U.S.C. $\S 2000$ (e) (1982). Although the statute does not define "discrimination," courts interpret Title VII as addressing two distinct types of behavior. The first, disparate treatment, occurs when an employer treats members of one race or sex different than members of another solely on account of race or sex. The second, disparate impact, oceurs when an employer uses criteria not designed to discriminate, but which have the effect of disproportionately impacting a specific group, unless the 
The notion that women naturally inhabit a separate sphere lasted longer. As late as 1961, the Supreme Court was still using the "fact" that "woman is still regarded as the center of home and family life" as a rationale for legal decisions. ${ }^{62}$ Not until ten years later, in Reed $v$. Reed ${ }^{63}$ did the Court finally start to break down separate sexual spheres ideology. It has still never fully adopted the idea that women have no important natural differences from men. ${ }^{64}$ Thus, while the Court has held that a state may not automatically prefer men over women as estate administrators, because women are not naturally different from men with regard to estate administration, ${ }^{65}$ it has held that a state may automatically prefer men over women as prison guards, because women are naturally different from men with regard to prison guarding. ${ }^{66}$

While separate spheres ideology has historically disadvantaged both Blacks and women, the nature of the disadvantage and the method of its imposition have differed substantially. It kept Blacks out of white law schools and white railway cars, ${ }^{67}$ while keeping white women at home and Black women invisible. ${ }^{68}$ Blacks were kept out of white society as a class; women were kept out of male society in public, but lived in intimate association with men in private. In this sense, then, Blacks were segregated together, while women were segregated individually. ${ }^{69}$

Similarly, the breakdown of separate spheres has proceeded differently for the two classes. At least in theory, it has meant a rejection of

criteria are justified as job related or necessary to the safe and efficient operation of the employer's business. See, e.g., International Bd. of Teamsters v. United States, 431 U.S. 324, 335 n.15 (1977); see also Griggs v. Duke Power Co., 401 U.S. 424 (1971) (testing requirement resulting in a disproportionately white workforce raised a presumption of discrimination because the Court could not entertain the notion that Blacks were naturally unfit for particular jobs) (discussed infra Part IV).

62. Hoyt v. Florida, 368 U.S. 57, 62 (1961) (upholding a priori exemption of women from jury service) (implicitly overruled by Alexander v. Louisiana, 405 U.S. 625 (1972)).

63. 404 U.S. 71 (1971) (striking down a statutory preference for male estate administrators).

64. Neither has Congress. Title VII contains an explicit exception that allows employers to exclude members of one sex from a particular job if sex is a "bona fide oeeupational qualification" for the job. There is no such exception for race in the statute. 42 U.S.C. $\S 2000 \mathrm{e}-2 \mathrm{e}$.

65. Reed, 404 U.S. 71 (1971) (only permissible rationale for preferenee was administrative convenience).

66. Dothard v. Rawlinson, 433 U.S. 321, 335 (1977) (female prison guards' very "womanhood" would make them ineffective in a prison with convicted sex offenders).

67. Ironically, it did not even keep all Black women out of the white railway cars, as there was usually an exception for Black nurses travelling with the white children they were caring forremember, these rules were for the convenience of whites. See Plessy v. Ferguson, 163 U.S. 537, 541 (1896).

68. See P. GidDings, supra note 49, at 15 ("[s]he had nothing to fall back on; not maleness, not whiteness, not ladyhood, not anything. And out of the profound desolation of her reality she may well have invented hersetf.") (quoting Toni Morrison).

69. Separate spheres ideology thus created a double barrier between Black and white women, a legacy the women's movement has not yet overcome. See This Bridge Called My Back (C. Moraga \& C. Anzalda eds. 1981). The ideology denied the necessity or desirability of bonds between women as well as between races. 
any natural differences between races, but it has meant a rejection of only some natural differences between sexes. ${ }^{70}$ The difference between Lochner v. New York, ${ }^{71}$ in which the Supreme Court struck down protective legislation for workers on "freedom of contract" grounds, and Muller v. Oregon, ${ }^{72}$ in which the Court upheld similar legislation for women, was the perceived incapacity of women-a perception that even today continues to justify the exclusion of women from some areas of social life. ${ }^{73}$ It is little wonder, then, that the spectre of a return to separate spheres ideology looms so large in any discussion of what feminists should do on behalf of women. ${ }^{74}$

\section{B. Feminist Responses}

Feininist legal theory has been primarily reactive, responding to the development of legal racial equality theory. The form of response, however, has varied. One response has been to attempt to equate legal treatment of sex with that of race and deny that there are in fact any significant natural differences between women and men; in other words, to consider the two sexes symmetrically located with regard to any issue, norm, or rule. ${ }^{75}$ This response, which I term the "symmetrical" approach, classifies asymmetries as illusions, "overbroad generalizations," or temporary glitches that will disappear with a little behavior modification. ${ }^{76} \mathrm{~A}$ competing response rejects this analogy, accepting

70. See Note, supra note 26 , at 504-06 (comparing the "separate is inherently unequal" approach of Brown v. Board of Educ., 347 U.S. 483 (1954), with the "separate but equal" approach of Vorchheimer v. School Dist., 532 F.2d 880 (3d Cir. 1976), aff'd by an equally divided Court, 430 U.S. 703 (1977) (female plaintiff's challenge to all-male public high school)). Interestingly enough, when a male plaintiff challenged sex segregation in a public university, the Court responded more positively, although hardly in the ringing tones of Brown. See Mississippi Univ. for Women v. Hogan, 458 U.S. 718 (1982). The issue is complicated by the fact that all-female institutions are frequently chosen by women as a challenge to the hegemony of the "male curriculum." See F. Howe, Why Educate Women?, in MYTHS OF COEDUCATION 259 (1984) (contrasting Wellesley and Stanford in their ability to offer female students an equal education).

71. 198 U.S. 45 (1905).

72. 208 U.S. 412 (1908).

73. See, e.g., Dothard v. Rawlinson, 433 U.S. 321 (1977); see also Harriss v. Pan Am. World Airways, 649 F.2d 670 (9th Cir. 1980) (flight attendants may be prohibited from flying when pregnant due to risk of "spontaneous abortion" endangering passengers).

74. See, e.g., Williams, The Equality Crisis, supra note 27, at 190-97.

75. In the 1970's, the first wave of feminist litigators chose this approach, and this led to the rather counterintuitive use of male plaintiffs in most of the major constitutional sex discrimination cases of the 1970's. See, e.g., Califano v. Goldfarb, 430 U.S. 199 (1977); Weinberger v. Wiesenfeld, 420 U.S. 636 (1975); Kahn v. Shevin, 416 U.S. 351 (1974). For a sympathetic interpretation of this phenomenon, see Cole, Strategies of Difference: Litigating for Women's Rights in a Man's World, 2 J.L. \& INEQUALITY 33, 53-92 (1984).

76. While many adherents of this approach view currently perceived differences between women and men as simply mistakes in perception which should be ignored, others claim that such differences do in fact exist, but should be eliminated through such methods as nonsexist childrearing and education. 
that women and men are or may be "different," and that women and men are often asymmetrically located in society. ${ }^{77}$ This response, which I term the "asymmetrical" approach, rejects the notion that all gender differences are likely to disappear, or even that they should.

\section{Symmetrical Models of Sexual Equality}

Feminist theorists frequently take the symmetrical approach to sexual equality, not as an ideal, but as the only way to avoid returning to separate spheres ideology. For example, in her highly compelling defense of symmetry in the law, Wendy Williams warns that "we can't have it both ways, we need to think carefully about which way we want to have it."78

There are two models of the symmetrical vision-referred to here as "assimilation" and "androgyny." Assimilation, the model most often accepted by the courts, ${ }^{79}$ is based on the notion that women, given the chance, really are or could be just like men. ${ }^{80}$ Therefore, the argument runs, the law should require social institutions to treat women as they already treat men-requiring, for example, that the professions admit women to the extent they are "qualified," but also insisting that women who enter time-demanding professions such as the practice of law sacrifice relationships (especially with their children) to the same extent that male lawyers have been forced to do. ${ }^{81}$

Androgyny, the second symmetrical model, also posits that women and men are, or at least could be, very much like each other, but argues that equality requires institutions to pick some golden mean between the two and treat both sexes as androgynous persons would be treated. ${ }^{82}$

77. Asymmetries in areas such as responsibility for childrearing need not, of course, be attributed to nature, but rather to the complex combination of legal, social, and psychological incentives presented to women and men. Asymmetrists do not necessarily deny that sex differences are alterable, but they do reject the notion that equality must await their disappearance.

78. Williams, The Equality Crisis, supra note 27, at 196 (emphasis added).

79. See, e.g., Hopkins v. Price Waterhouse, 618 F. Supp. 1109 (D.D.C. 1985). The court had no difficulty deciding that a female candidate denied partnership in an accounting firm had been discriminated against where several of the partners criticized her for displaying "masculine characteristic[s]." Id. at 1118.

80. Harriet Taylor Mill, well ahead of her time, nonetheless urged only that legal restrictions on women's employment be abandoned, leaving in place the obvious "incompatibility" of motherhood and employment. Mill, Enfranchisement of Women, in ESSAYS ON SEX EQUALITY 91, 103-04 (A. Rossi ed. 1970). Perhaps enfranchisement was only to apply to single women.

81. But see Project, Law Firms and Lawyers with Children: An Empirical Analysis of Family/ Work Conflict, 34 STAN. L. REv. 1263, 1300 (1982) (finding an "increased willingness" among private law firms to consider flexible work arrangements for women, but "little evidence" for accommodating men as co-equal parents). Cf. Taub, From Parental Leaves to Nurturing Leaves, 13 N.Y.U. REV. L. \& Soc. CHANGE 381, 381 (1985) (arguing for "a comprehensive, nationally funded system of compassionate or nurturing work leaves to permit and support a variety of increasingly needed caregiving services" so that neither women nor men will have to undergo such sacrifices).

82. For example, Wendy Williams describes the "equal treatment" response to the pregnancy 
However, given that all of our institutions, work habits, and pay scales were formulated without the benefit of substantial numbers of androgynous persons, ${ }^{83}$ androgynous symmetry is difficult to conceptualize, and might require very substantial restructuring of many public and private institutions. ${ }^{84}$ In order to be truly androgynous within a symmetrical framework, social institutions must find a single norm that works equally well for all gendered characteristics. Part of my discomfort with androgynous models is that they depend on "meeting in the middle," while I distrust the ability of any person, and especially any court, to value women enough to find the "middle." 85 Moreover, the problems involved in determining such a norm for even one institution are staggering. At what height should a conveyor belt be set im order to satisfy a symmetrical androgynous ideal? ${ }^{86}$

Symmetry appears to have great appeal for the legal system, ${ }^{87}$ and

in the workplace dilemma as androgynous because it promotes the "normalization" of pregnancy. Williams, Equality's Riddle, supra note 2, at 363 . By treating disability arising from pregnancy just like disability arising from illness and injury, the equal trcatment model "incorporat[es] pregnancy into the existing benefit schemes." Id. But it is the existence of male-oriented benefit schemes that makes treating pregnancy like a hernia look like "normalizing" it. And, of course, if the "existing benefit schemes" are paltry or insufficient, then women share the burden of illness and injury while carrying the whole burden of procreation. Escaping from the male norm is not as easy as it looks.

83. See Blank v. Sullivan \& Cromwell, 418 F. Supp. 1, 4 (S.D.N.Y. 1975) (Hon. Constance Baker Motley's denial of motion to recuse for bias in sex discrimination case, based in part on "jurisdiction by necessity" argument).

84. See, e.g., Rossi, Sex Equality: The Beginnings of Ideology, in BEYOND SEX-ROLE STEREOTYPES 80, 87 (A. Kaplan \& J. Bean eds. 1976); Taub, supra note 81, passim (suggesting a restructuring of the way academic progress is measured).

85. For example, in the speculative fantasy The Left Hand of Darkness (1969), U.K. LeGuin portrays a world in which people are "androgynous," taking on either male or female reproductive functions at various times. Yet, in reading the tale, I simply could not stop thinking of these characters as male. Perhaps the problem is best summed up in Catharine Hantzis' description of the gender dilemma: "(W)e collectively lack a vision of a person who is virtuous, active, powerful, happy, and not male." Hantzis, Is Gender Justice a Completed Agenda? (Book Review), 100 HARV. L. REV. 690, 698 (1987) (footnote omitted) (reviewing E. LENZ \& B. MYERHOFF, ThE FEMinization OF AMERICA (1985)).

86. Some feminists hold out an ideal of asymmetrical androgyny. See, e.g., Olsen, The Family and the Market: A Study of Ideology and Legal Reform, 96 HARV. L. REV. 1497, 1578 (1983) (androgyny as "reds and greens and blues" rather than undifferentiated gray). Shifting to an asymmetrical framework, however, changes the ideal of androgyny into the ideal of equal acceptance. See infra text accompanying notes 172-78.

87. For example, in Sexual Harassment of Working Women, supra note 28, Catharine MacKinnon offered two separate theories under which sexual harassment could be accepted as sex discrimination-one symmetrical and the other asymmetrical. Id. at 106-26. (Interestingly enough, MacKinnon refers to the symmetrical model as a "differences" approach and the asymmetrical model as an "inequality" approach. Id. at 106-16.) Under a symmetrical theory, sexual harassment is sex discrimination because the harasser (usually male) is treating the harassee (usually female) differently than he would a member of the other sex. Under an asymmetrical theory, sexual harassment is sex discrimination because it systematically deprives women of employment opportunities. In Barnes v. Costle, 561 F.2d 983 (D.C. Cir. 1977) and Bundy v. Jackson, 641 F.2d 934 (D.C. Cir. 1981), the D.C. Circuit adopted the symmetrical version, an approach other courts have consistently followed. 
this is not surprising. The hornbook definition of equal protection is "that those who are similarly situated be similarly treated,"88 and many courts, following the Supreme Court's lead, have held that absent a showing of similarity, strict scrutiny is simply inapplicable. ${ }^{89}$ Symmetrical analysis also has great appeal for liberal men, ${ }^{90}$ to whom it appears to offer a share in the feminist enterprise. ${ }^{91}$ If perceived difference between

88. Tussman \& tenBroek, The Equal Protection of the Laws, 37 CAL1F. L. REv. 341,344 (1949). Tussman \& tenBroek also critiqued that formulation as begging the question, id. at 344-46, but their critique is less well-known than their restatement of the law.

89. See, e.g., Rostker v. Goldberg, 453 U.S. 57 (1981); Michael M. v. Superior Court, 450 U.S. 464 (1981) (both holding strict scrutiny inapplicable to classifications based on actual or legal differences between the sexes).

90. The least critical symmetrical approaches are found in the work of male legal theorists. Richard Wasserstrom, for example, envisions the sexually equal society as one in which biological sex is "no more significant than eye color," and in which asking whether a new baby is a boy or a girl is no more common than asking whether it has large or small feet. Wasserstrom, supra note 52, at 606. Wasserstrom does recognize a problem with his "assimilationist" ideal. "That term suggests the idea of incorporating oneself, one's values, and the like into the dominant group and its practices and values. I want to make it clear that no part of that idea is meant to be captured by my use of this term." Id. at 604 n.46. Unfortunately, his prescription of ignoring difference leaves unanalyzed and uncriticized the phallocentric value hierarchy that consistently disadvantages women. Id. at 611 . Despite his protestations, Wasserstrom's assimilationist ideal, as developed in the text of his article, is precisely the one he claims to reject.

91. The question of the extent to which men can "do" feminism (as opposed to writing about feminism) is itself a matter of debate within the feminist community. Naomi Schorr's recent review of K. RuthVEN, FEMINIST Literary Studies: AN INTRODUCTION (1984) and T. Mol, SEXUAL/ TEXTUAL POLITICS: FEMINIST LITERARY THEORY (1985) provides a brief sketch of how this debate rages within the field of feminist literary criticism. See N. Schorr, Introducing Feminism (1986) (unpublished manuscript on file with the author). Pro-feminist men play an important role in disseminating and implementing feminist ideas. But as to whether men can speak as feminists-i.e., speak from the perspective of women's experience-my own position is as follows: $I$ take the experience of living a goodly number of years as a woman to be a necessary, but not sufficient, prerequisite of feminism. Ergo, on my definition, men would have to give up their class status in some nontemporary way in order to meet the minimum qualifications. This does not appear to me to have occurred to any significant degree.

A somewhat different (and less exasperating) question than whether men can be feminists is whether anyone other than feminists can make a meaningful contribution to discourse about scxual equality. The answer to this question is clearly yes. While feminism, and thus feminist equality theory, is necessarily built on the experience of women analyzed from the perspective of women as a class (i.e., from the feminist perspective), women do not occupy the world alone.

The experience of nonfeminist women is obviously relevant to building feminist theory. Indeed, Andrea Dworkin, herself a radical feminist, has brilliantly translated the experience of non- (and perhaps anti-) feminist women, breaking down some of the suspicion and hostility with which many feminists view their dissenting sisters. A. DWORKIN, RIGHT-WING WOMEN (1983).

It is also necessary to understand the experience of men in this society if feminism is ever to break down the barriers between male and female experience. Feminists do not resent men's attempts to report their experience with the social process of oppression. What we do resent is the (unfortunately frequent) assertion by men that their experience is in fact ours. The oppression suffered by a white male law student at the hands of an authoritarian professor is real; it is not, however, the same as that of students who are not white and male. Those men who are truly interested in entering the dialogue of liberation will make sincere efforts to leave behind the socially male tendency to view their own particular experience as experience per se and the experience of others as distorted. 
the sexes is only the result of overly rigid sex roles, then men's liberty is at stake too. ${ }^{92}$ Ending this form of sexual inequality could free men to express their "feminine" side, just as it frees women to express their "masculine" side.

\section{Asymmetrical Models of Sexual Equality}

Asymmetrical approaches to sexual equality take the position that difference should not be ignored or eradicated. Rather, they argue that any sexually equal society must somehow deal with difference, problematic as that may be. Asymmetrical approaches include "special rights," "accommodation," "acceptance," and "empowerment."

The special rights model affirms that women and men are different, and asserts that cultural differences, such as childrearing roles, are rooted in biological ones, such as reproduction. Therefore, it states, society must take account of these differences and ensure that women are not punished for them. This approach, sometimes referred to as a "bivalent" model, ${ }^{93}$ is closest to the "special treatment" pole of the asymmetrical/ symmetrical equality debate. Elizabeth Wolgast, a major proponent of special rights, argues that women cannot be men's "equals" because equality by definition requires sameness. ${ }^{94}$ Instead of equality, she suggests seeking justice, claiming special rights for women based on their special needs. ${ }^{95}$

The second asymmetrical model, accommodation, agrees that differential treatment of biological differences (such as pregnancy, and perhaps breastfeeding) is necessary, but argues that cultural or hard-to-classify differences (such as career interests and skills) should be treated under an equal treatment or androgynous model. Examples of accommodation

92. Though both men and women are harmed in similar ways by the rigidity of sex stereotypes, it is men's liberty interest that is infringed, not their equality interest. See infra Part III. And the liberty interest of men is hardly infringed to the same degree as most women's. See, e.g., M. FRYE, The Politics of Reality (1983) (describing interlocking restrictions on women's lives).

93. See Scales, supra note 40 , at $430-34$; see also E. WolgAST, EQUALITY AND THE RIGHTS of WOMEN 61-63 (1980).

94. E. WOLGAST, supra note 93, at 122 ("Consider, if both men and women are taught about the delivery of a baby, and both are taught to 'participate' in it, their roles will still be sexdifferentiated. And similarly, there will be some sex-differentiation in parenthood.")

95. The rights needed by women in different life forms will differ. The wife and homemaker will need some special provisions for her old age; the career woman will not need these, but will need equal rights with respect to work. The woman who pursues a part-time career will need both kinds of rights less urgently; the woman whose career begins late will have a special set of needs again; while the divorced mother's needs are probably the greatest of all.

Id. at 157.

Wolgast's argument relies on an analogy to the condition of disabled persons rather than the analogy to Blacks. It thus also fails to ground the claims of women as a class in our own situation and, ironically, reintroduces notions of similarity. 
models include Sylvia Law's approach to issues of reproductive biology ${ }^{96}$ and Herma Hill Kay's "episodic" approach to the condition of pregnancy. ${ }^{97}$ These approaches could also be characterized as "symmetry, with concessions to asymmetry where necessary." The accommodationists limit the asymmetry in their models to biological differences because, like Williams, they fear a return to separate spheres ideology should asymmetrical theory go too far. ${ }^{98}$

My own attempt to grapple with difference, which I call an "acceptance" model, ${ }^{99}$ is essentially asymmetrical. While not endorsing the notion that cultural differences between the sexes are biologically determined, it does recognize and attempt to deal with both biological and social differences. Acceptance does not view sex differences as problematic per se, but rather focuses on the ways in which differences are permitted to justify inequahity. It asserts that eliminating the unequal consequences of sex differences is more important than debating whether such differences are "real," or even trying to eliminate them altogether.

Unlike the accommodationists, who would limit asymmetrical analysis to purely biological differences, my proposal also requires equal acceptance of cultural differences. The reasons for this are twofold. First, the distinction between biological and cultural, while useful analytically, is itself culturally based. Second, the inequality experienced by women is often presented as a necessary consequence of cultural rather than of biological difference. If, for instance, women do in fact "choose" to become nurses rather than real estate appraisers, ${ }^{100}$ it is not because of

96. Law, Rethinking Sex and the Constitution, 132 U. PA. L. REv. 955, 1007-13 (1984) (calling for equal treatment in all areas except reproduction, where an analysis based on an empowerment approach, see supra text accompanying notes 117-22, should be adopted).

97. Kay, Equality and Difference: The Case of Pregnancy, 1 BERKELEY WOMEN's L.J. 1, 27-37 (1985) (sex differences should be ignored, except during the time a female is actually pregnant).

98. See, e.g., id. at 22 (distinguishing the author's approach from one that might support separate spheres).

99. At one time, I called this model of equality one of "affirmation." See C. Littletoll, Alternative Models of Sexual Equality, Address delivered at the Clara Brett Martin Workshop, University of Toronto (1984) (on file with the author). I have changed the terminology, however, because I am not advocating a "celebration" of women's difference, or even pushing the subversive potential of "jouissance." See INTRODUction To FRENCH FEminisms, supra note 2, at 3; D. Cornell, Equality and Gender Difference: Towards a Critical Theory of Equality 17 (1983) (unpublished manuscript on file with the author). Such celebrations look too much like embracing our oppression when women do it, and too much like condescension when men do. See supra text accompanying notes $72-73$ (discussing Muller v. Oregon, 208 U.S. 412 (1908)). Nor am I calling for an inversion of the hierarchical ordering of male and female modes of being (although I might not object to one). It does, however, seem affirming to be simply (simply?) accepted for what one is, not pushed into one side or the other of the great gender divide by economic and social pressures. At the risk of making it sound like too little to ask, then, 1 have chosen to call the model one of "acceptance."

100. See Lemons v. City \& County of Denver, 17 Fair Empl. Prac. Cas. (BNA) 906 (D. Colo. Apr. 17, 1978) (rejecting a comparable worth claim that paying nurses less that real estate appraisers violates Title VI1). 
any biological imperative. Yet, regardless of the reasons for the choice, they certainly do not choose to be paid less. It is the consequences of gendered difference, and not its sources, that equal acceptance addresses.

If, as it appears from Gilligan's studies, ${ }^{101}$ women and men tend to develop somewhat differently in terms of their values and inclinations, each of these modes of development must be equally valid and valuable. In our desire for equality, we should not be forced to jettison either; rather, we should find some way to value both. That such different modes do not perfectly correspond to biological sex does not prevent them from being typed socially as "male" and "female," and neither should it prevent us from demanding that they be equally valued. Thus, if women currently tend to assume primary responsibility for cliildrearing, we should not ignore that fact in an attempt to prefigure the rosy day when parenting is fully shared. We should instead figure out how to assure that equal resources, status, and access to social decisionmaking flow to those women (and few men) who engage in this socially female behavior.

The focus of equality as acceptance, therefore, is not on the question of whetler women are different, but rather on the question of how the social fact of gender asymmetry can be dealt with so as to create some symmetry in the lived-out experience of all members of the community. I do not think it matters so much whether differences are "natural" or not; they are built into our structures and selves in either event. ${ }^{102}$ As social facts, differences are created by the interaction of person witl person or person with institution; they inhere in the relationship, not in the person. ${ }^{103}$ On this view, the function of equality is to make gender differences, perceived or actual, costless relative to each other, so that anyone may follow a male, female, or androgynous lifestyle according to their natural inclination or choice witlout being punislied for following a female lifestyle or rewarded for following a male one.

As an illustration of this approacl, consider what many conceive to be the paradigm difference between men and women-preguancy. No one disputes that only women become pregnant, but symmetrical theorists analogize pregnancy to other events, in order to preserve the unitary approach of symmetrical theory. ${ }^{104}$ Such attempts to minimize difference liave the ironic result of obscuring more fundamental similarities.

In California Federal Savings \& Loan Association v. Guerra (Cal. Fed.), ${ }^{105}$ Lillian Garland, a receptionist at California Federal tried to

101. See C. Gilligan, supra note 11.

102. Furthermore, which differences are "real" and which are "perceived" seems to shift from place to place and decade to decade. See Note, supra note 26, at 497-98 \& nn.55-57.

103. I am grateful to Professor Martha Minow for this insight.

104. See supra note 82.

105. 107 S. Ct. 683 (1987). 
return to her job after the birth of her child. The bank refused to reinstate her, and she sued under the California Fair Employment and Housing Act (FEHA). ${ }^{106}$ That law requires that employees temporarily disabled by pregnancy be given an unpaid leave of up to four months, with guaranteed reinstatement in their original job or its equivalent. ${ }^{107}$ The bank in turn sued in federal court, claiming that the FEHA was preempted by Title VII of the Civil Rights Act of $1964,{ }^{108}$ as amended by the Pregnancy Discrimination Act (PDA). The PDA requires only that employers treat pregnancy the same as any other disability. ${ }^{109}$ California Federal argued that the PDA prevented California from enforcing its pregnancy disability leave requirements against firms that did not provide these benefits for disabilities unrelated to pregnancy. ${ }^{110}$

In addition to narrow questions of statutory interpretation, $\mathrm{Cal}$. Fed. raised more fundamental questions about the meaning of equal employment opportunity for women. Citing the dangers of separate spheres ideology raised by "protectionist" legislation, the national ACLU filed an amicus brief arguing that the California law should be struck down, and that the remedy should provide for job-protected leave for all temporarily disabled employees, whatever the source of their disability. ${ }^{11}$ California feminist groups, such as Equal Rights Advocates, filed on the other side of the debate, arguing that the California law guaranteed equality of opportunity, and was thus consistent with federal law and policy. ${ }^{112}$

Missing in these arguments, however, was any recognition that working men and women shared a more fundamental right than the right

106. CAL. Gov'T CODE $\S \S 12900-12996$ (West 1980 \& Supp. 1987).

107. § $12945(\mathrm{~b})(2)$.

108. 42 U.S.C. $\S \S 2000 \mathrm{e}-10$ to -17 (1982).

109. Pub. L. No. 95-555, 92 Stat. 2076 (1978) (codified at 42 U.S.C. $\$ 2000 \mathrm{e}(\mathrm{k})$ ). The PDA was enacted in 1978 to prevent the then common practice of excluding pregnancy from employee health and disability insurance plans and other employment benefits. See General Elec. Co. v. Gilbert, 429 U.S. 125 (1976) (exclusion of pregnancy benefits from disability plan not gender-based discrimination under Title VII); Geduldig v. Aiello, 417 U.S. 484 (1974) (exclusion of pregnancy benefits from state disability plan not unconstitutionally underinclusive). While the first prong of the PDA simply defines discrimination on the basis of pregnancy as a form of sex discrimination, the second prong specifies that "women affected by pregnancy, childbirtl, or related medical conditions shall be treated the same for all employment-related purposes ... as other persons not so affected but similar in their ability or inability to work." 42 U.S.C. $\$ 2000 \mathrm{e}(\mathrm{k})$ (1982).

110. Cal. Fed., 107 S. Ct. at $688,692$.

111. Brief for the ACLU as amicus curiae, Cal. Fed., 107 S. Ct. 683 (1987) (No. 85-494). In this case, the Union did not represent the views of its largest affiliate, the ACLU of Southern California, which has consistently supported the pregnancy disability legislation. See id. at A-2. The National Organization for Women made a similar argument, suggesting that state and federal law could be reconciled by requiring the employer to provide leave for disability arising from any source. Brief for the National Organization for Women as amicus curiae, Cal. Fed., 107 S. Ct. 683 (1987) (No. 85494).

112. Brief for Equal Rights Advocates as amicus curiae, Cal. Fed., 107 S. Ct. 683 (1987) (No. 85-494). 
to basic disability leave benefits or job protection. The Coalition for Reproductive Equality in the Workplace (CREW) advanced the position that working women and men share a right to procreative choice in addition to an interest in disability leave. ${ }^{113}$ In order to ensure equal exercise of procreative rights, it argued, an employer must provide leave adequate to the effects of pregnancy.

The California statute eliminates barriers to equality in both procreation and employment faced by women who cannot afford to lose their jobs when they decide to become parents. Male employees who become fathers and female employees who become mothers are thus enabled to combine procreation and employment to the same extent. ${ }^{114}$

This form of acceptance, unlike those that analogize pregnancy to disability, emphasizes the basic commonality of procreation as a human endeavor involving both women and men. By recognizing pregnancy as "different" from other causes of disability, it supports efforts to equalize the position of working women and men with respect to this fundamental right. ${ }^{115}$

The foregoing asymmetrical models, including my own, share the notion that, regardless of their differences, women and men must be treated as full members of society. Each model acknowledges that women may need treatment different than that accorded to men in order to effectuate their membership in important spheres of social life; all would allow at least some such claims, although on very different bases, and probably in very different circumstances. ${ }^{116}$

A final asymmetrical approach, "empowerment," rejects difference altogether as a relevant subject of inquiry. ${ }^{117}$ In its strongest form,

113. Brief for the Coalition for Reproductive Equality in the Workplace (CREW) as amicus curiae, Cal. Fed., 107 S. Ct. 683 (1987) (No. 85-494). I was the attorney of record for CREW, and the principal author of the CREW amicus brief.

114. Id. at 36-37.

115. The Cal. Fed. opinion, authored by Justice Marshall, does much to bring together the asymmetrical and symmetrical equality arguments. As alternative holdings, the opinion first defends the California law as consistent with equal employment opportunity. "By "taking pregnancy into account,' California's pregnancy disability leave statute allows women, as well as men, to have families without losing their jobs." $107 \mathrm{~S}$. Ct. at 694. The Court then states that the employer can satisfy both California law and demands for symmetry by providing leave for all forms of disability. Id. at 694-95.

116. For example, Herma Hill Kay argues that differential treatment must be strictly limited to pregnancy, breastfeeding, menstruation, and rape. Kay, Models of Equality, 1985 U. ILL. L. REV. 39, 81 (1985).

117. This model has been articulated most fully by Catharine MacKinnon, and draws heavily on the work of radical feminist theorists such as Andrea Dworkin. See C. MACKInNon, supra note 28 (examining sexual harassment in context of male power structure); MacKinnon, Feminism, Marxism, Method and the State: Toward Feminist Jurisprudence, 8 SIGNS 635 (1983) (examining how traditional theories of "the state" perpetuate male power to exclude women's perspective) [hereinafter MacKinnon, Toward Feminist Jurisprudence]; A. DwORkIN, OuR BLOoD 96-111 (1976); A. Dworkin, Pornography: Men Possessing Women 13-24 (1979) [hereinafter A. DWORKIN, PORNOGRAPHY]. 
empowerment claims that the subordination of women to men has itself constructed the sexes, and their differences. For example, Catherine MacKinnon argues:

[I]t makes a lot of sense that women might have a somewhat distinctive perspective on social life. We may or may not speak in a different voice-I think that the voice that we have been said to speak in is in fact in large part the 'feminine' voice, the voice of the victim speaking without consciousness. But when we understand that women are forced into this situation of inequality, it makes a lot of sense that we should want to negotiate, since we lose conflicts. It makes a lot of sense that we should want to urge values of care, because it is what we have been valued for. We have had little choice but to be valued this way. ${ }^{118}$

A somewhat weaker version of the claim is that we simply do not and cannot know whether there are any important differences between the sexes that have not been created by the dynamic of domination and subordination. In either event, the argument runs, we should forget about the question of differences and focus directly on subordination and domination. If a law, practice, or policy contributes to the subordination of women or their domination by men, it violates equality. If it empowers women or contributes to the breakdown of male domination, it enhances equality. 119

The reconceptualization of equality as antidomination, like the model of equality as acceptance, attempts to respond directly to the concrete and lived-out experience of women. ${ }^{120}$ Like other asymmetrical models, it allows different treatment of women and men when necessary to effectuate its overall goal of ending women's subordination. ${ }^{121}$ How-

118. Feminist Discourse, supra note 13, at 27 (emphasis added).

119. This formulation has enabled MacKinnon to view sexual harassment, see C. MACK1NNON, supra note 28, at 142-213, rape, see Toward Feminist Jurisprudence, supra note 117, at 646-55, and pornography, see MacKinnon, Not a Moral Issue, 2 YAle L. \& PoL'Y Rev. 321, 337 (1984), as violations of women's civil rights.

120. See Feminist Discourse, supra note 13.

Consider that thirty-eight percent of young girls are sexually abused as children by older men in their dominant family unit with whom they are close. . . . About forty to forty-four percent of women are either raped-in the usual legal sense of the viord, not including marital rape-or are victims of an attempted rape. Around eighty-five percent of all Id. at 26.

women are, or have been, sexually harassed in the workforce at some point.

121. See, e.g., proposed amendment to Minneapolis, MinN., Code of Ordinances tit. 7 , chs. 139, 141 (1983) (copy on file with the California Law Review). This antipornography ordinance, written by Catharine A. MacKinnon and Andrca Dworkin, allows civil causes of action for damages to those injured by (1) coercion into making pornography, (2) forced viewing of pornography, (3) assault caused by pornography, and (4) trafficking in pornography. The last cause of action is available to any individual woman "acting against the subordination of women." Id. $\S 4$. Although men, children, and transsexuals may also sue under the ordinance, the trafficking provision is clearly framed to benefit women as a class, rather than to account for individual experiences of subordination that may be suffered by persons of either sex.

The proposal was twice passed by the Minneapolis City council, and twice vetoed by the mayor. For a brief history of the political fortunes of the ordinance, see Dworkin, Against the Male Flood: 
ever, it differs substantially from the acceptance model in its rejection of the membership, belonging, and participatory aspects of equality. ${ }^{122}$

\section{The Difference that Difference Makes}

Each of the several models of equality discussed above, if adopted, would have a quite different impact on the structure of society. If this society wholeheartedly embraced the symmetrical approach of assimilation-the point of view that "women are just like men"-little would need to be changed in our economic or political institutions except to get rid of lingering traces of irrational prejudice, such as an occasional employer's preference for male employees. In contrast, if society adopted the androgyny model, which views both women and men as bent out of shape by current sex roles ${ }^{123}$ and requires both to conform to an androgynous model, it would have to alter radically its methods of resource distribution. In the employment context, this might mean wholesale revamping of methods for determining the "best person for the job." Thus, while assimilation would merely require law firms to hire women who have managed to get the same credentials as the men they have traditionally hired, androgyny might insist that the firm hire only those persons with credentials that would be possessed by someone neither "socially male" nor "socially female." 124

If society adopted an asymmetrical approach such as the accommodation model, no radical restructuring would be necessary. Government would need only insist that women be given what they need to resemble men, such as time off to have babies and the freedom to return to work on the same rung of the ladder as their male counterparts. ${ }^{125}$ If, however, society adopted the model of equality as acceptance, which seeks to make difference costless, it might additionally insist that women and men who opt for socially female occupations, such as child-rearing, be compensated at a rate similar to those women and men who opt for socially male occupations, such as legal practice. Alternatively, such occupations might be restructured to make them equally accessible to those whose

Censorship, Pornography, and Equality, 8 HARv. Women's L.J. 1, 13 (1985) (editor's note); for a more detailed treatment, see Brest \& Vandenberg, Politics, Feminism and the Constitution: The AntiPornography Movement in Minneapolis, 39 STAN. L. REv. 607 (1987).

122. Nondomination does not require interaction; at most it only requires coexistence. Although I strongly support the right of women to choose separatism as a lifestyle, I want it to be a real choice.

123. Olsen, supra note 40 , at 10.

124. See Rossi, supra note 84 , at 87.

125. California's pregnancy disability leave statute, CAL. Gov'T CoDE $\S 12945$ (b) (West 1982), only requires employers to grant workers disabled by pregnancy a right to return to their original jobs after an unpaid leave. See supra text accompanying notes 104-15. 
behavior is culturally coded "male" or "female." "126

The different models also have different potential to challenge the phallocentrism of social institutions. No part of the spectrum of currently available feminist legal theory is completely immune to the feminist critique of society as phallocentric. We cannot outrun our history, and that history demonstrates that the terms of social discourse have been set by men who, actively or passively, have ignored women's voices-until even the possibility of women having a voice has become questionable. $^{127}$ Nevertheless, the models do differ with respect to the level at which the phallocentrism of the culture reappears.

Under the assimilationist approach, for example, women merit equal treatment only so far as they can demonstrate that they are similar to men. The assimilation model is thus fatally phallocentric. To the extent that women cannot or will not conform to socially male forms of behavior, they are left out in the cold. To the extent they do or can conform, they do not achieve equality as women, but as social males. ${ }^{128}$

Similarly, empowerment and androgyny (an asymmetrical and a symmetrical approach, respectively) both rely on central concepts whose current meaning is phallocentrically biased. If "power" and "neutrality" (along with "equality") were not themselves gendered concepts, the empowerment and androgyny approaches would be less problematic. But our culture conceives of power as power used by men, ${ }^{129}$ and creates androgynous models "tilted" toward the male. ${ }^{130}$ As Carrie MenkelMeadow put it, the trouble with marble cake is that it never has enough chocolate; the problem with androgyny is that it never has enough womanness. ${ }^{131}$ Similarly, empowering women without dealing with difference, like assimilation, too easily becomes simply sharing male power more broadly. ${ }^{132}$

Equality as acceptance is not immune from phallocentrism in several of its component concepts. However, these concepts are not neces-

126. Cf. Menkel-Meadow, supra note 13, at 55-58 (suggesting that "women's lawyering," though different from "men's lawyering," could be reinterpreted as "good lawyering").

127. See H. Cixous, Sorties, in French FeminismS, supra note 2, at 90, 91-92 (excerpts); L. IRIGARAY, supra note 2; cf. MacKinnon, supra note 119, at 337 ("That pornography chills women's expression is difficult to demonstrate empirically because silence is not eloquent.").

128. The phallocentricity of assimilation will be discussed in greater detail in Parts II and III, infra.

129. See infra text accompanying note 207.

130. See supra note 85 and accompanying text.

131. A. Allen, C. Littleton \& C. Menkel-Meadow, Law in a Different Voice, 15th National Conference on Women and the Law, Address by C. Menkel-Meadow (Mar. 31, 1984) (tape on file with the author).

132. Power as it has traditionally been exercised within a phallocentric culture is male power, even when exercised by women. See infra text accompanying notes 216-18. Unless our conception of power is transformed by a recognition of difference, see infra text accompanying notes 206-07, the empowerment of women runs the risk of becoming an improved form of assimilation. 
sarily entailed by the theory and may be replaced with less biased concepts as they reveal themselves through the process of equalization. For example, in discussing employment-related applications of the model, I use the measures already existing in that sphere-money, status, and access to decisionmaking. These measures of value are obviously suspect. Nevertheless, my use of them is contingent. Acceptance requires only that culturally coded "male" and "female" complements be equally valued; it does not dictate the coin in which such value should be measured. By including access to decisionmaking as part of the measure, however, the theory holds out the possibility that future measures of value will be created by women and men together. Thus, acceptance strives to create the preconditions necessary for sexually integrated debate about a more appropriate value system.

The various models of equality arise out of common feminist goals and enterprises: trying to imagine what a sexually equal society would look like, given that none of us has ever seen one; and trying to figure out ways of getting there, given that the obstacles to sexual equality are so many and so strong.

The perception among feminist legal thinkers that the stakes in the symmetrical vs. asymmetrical debate are high is correct. Difference indeed makes a difference. Yet, the frantic nature of the debate about difference between the sexes makes the divergent views within feminist legal thought appear as a deadly danger rather than an exciting opportunity. ${ }^{133}$ The label "divisive" gets slapped on before the discussion even gets underway.

We need to recognize difference among women as diversity rather than division, ${ }^{134}$ and difference between women and men as opportunity rather than danger. Audre Lorde calls for the recognition of difference among women in terms that should apply to all human difference:

As a tool of social control, women have been encouraged to recognize only one area of human difference as legitimate, those differences which exist between women and men. And we have learned to deal across those differences with the urgency of all oppressed subordinates. ... We have recognized and negotiated these differences, even when this recognition only continued the old dominant/subordinate mode of human relationship, where the oppressed must recognize the masters' difference in order to survive.

\section{But our future survival is predicated upon our ability to relate within}

133. See Krieger \& Cooney, supra note 40 , at 513 (noting that the Chinese term for "crisis" is composed of the characters for "danger" and "opportunity").

134. As Hester Eisenstein has stated, the paradox of women's studies has been that commonality among women was necessary in order to establish a need for the discipline, but taking women as the unit of analysis for research has uncovered the endless variety of our experience. THE FUTURE OF DIFFERENCE xvi-xviii (H. Eisenstein \& A. Jardine eds. 1985). 
equality. ${ }^{135}$

There must be choices beyond those of ignoring difference or accepting inequality. So long as difference itself is so expensive in the coin of equality, we approach the variety of human experience with blinders on. ${ }^{136}$ Perhaps if difference were not so costly, we, as feminists, could think about it more clearly. Perhaps if equality did not require uniformity, we, as women, could demand it less ambivalently.

II

\section{EQUALITY AND DifFERENCE}

Part I focused on the range of feminist reactions to, and attempts to work within, current equality analysis. This Part focuses on the feminist critique of equality analysis from the "outside"-that is, from a perspective that is "other" to the male construction of law and social norms. ${ }^{137}$ From this viewpoint, the very notion of "equality" as currently accepted by the culture appears phallocentric, fatally constrained by the terms of public discourse that historically have been set solely by men. In Part I, I presented the acceptance model of equality as an alternative to mainstream equality doctrine. In this Part, I explain how that model derives from the feminist critique of equality and responds directly to its primary strands.

\section{A. Feminist Critique of Equality}

The phallocentricity of equality is most apparent in the extraordinary difficulty the legal system has had dealing with the fact that women (and not men) conceive and bear children. Indeed, it would not be necessary to go further than to establish that the legal system has had difficulty with this fact in order to ground the claim that equality analysis is phallocentric. It is, however, necessary to go beyond a simple recounting of the law in this area in order to lay out the particular ways in which the phallocentricity is manifested.

I have argued elsewhere ${ }^{138}$ that the Supreme Court's decision in Reed v. Reed ${ }^{139}$ marked its acceptance of the "assimilationist" model of sexual equality. ${ }^{140}$ That decision was profoundly assimilationist in that

135. A. LORDE, Age, Race, Class and Sex: Women Redefining Difference, in SISTER OUTSIDER, supra note 38, at 114, 122 (emphasis added).

136. See supra text accompanying notes 104-15 (fear of recognizing difference leads to failure to recognize deeper forms of commonality).

137. See generally S. DE BEAUVoIR, supra note 35 (arguing that men have created woman as man's "other"); $c f$. Crenshaw, supra note 24 (finding a need for rights discourse that encompasses the "other" in the racial context).

138. Note, supra note 26 , at 502-03.

139. 404 U.S. 71 (1971).

140. See supra notes 63-65 and accompanying text. 
the Court rejected as "irrational" the view that women might be different from men with respect to their ability to handle the traditionally "male" responsibilities of estate administration.

The first cases to reach the Supreme Court after its about-face in Reed did not present questions that challenged this assimilationist model. ${ }^{141}$ In Craig v. Boren, ${ }^{142}$ for example, the Court saw the differences in driving patterns of male and female teenage drinkers not as a significant difference, but rather as one that could readily be ignored, thus failing to provide a substantial "fit" between the difference and the differential classification. Similarly, those classifications that were upheld by the Court were justified as temporary measures to reduce differences that were not intractable. Thus, in Kahn v. Shevin, ${ }^{143}$ Florida's tax subsidy to widows (and not widowers) was upheld as a reasonable atteinpt to compensate the spouse who would most severely feel the econoinic loss of the other partner to the marriage, a difference that would disappear once sex discrimination is gone from our society. Temporary alleviation of socially created (and socially remediable) differences between the sexes is simple affirmative action. Its goal is symmetry of the sexes, achieved through temporary asymmetrical treatment. Under this view, had men been irrationally discriminated against in employment, it might just as easily have been the widowers rather than the widows who needed the tax break.

When challenges arose to pregnancy-based classifications, however, the Court was faced with a difference that it could not ignore or treat as created by irrational discrimination. ${ }^{144}$ In Geduldig $v$. Aiello ${ }^{145}$ and General Electric Co. v. Gilbert, ${ }^{146}$ the Supreme Court announced, apparently with a straight face, that singling out pregnancy for disadvantageous treatinent was not discrimination on the basis of sex. ${ }^{147}$ Underlying both

141. Cf. Williams, The Equality Crisis, supra note 27, at 179-80 (characterizing these as the "easy cases").

142. 429 U.S. 190 (1976); see Note, supra note 26, at 503.

143. 416 U.S. 351 (1974).

144. No amount of nondiscrimination or temporary affirmative action will ever make it possible for men to bear children. Of course, increasing technological intervention might eventually provide for this possibility. Some feminist utopian writers seem to see the possibility of male pregnancy, or at least male breastfeeding, as a crucial part of a sexually equal society. See, e.g., U. K. LEGuIN, supra note 85 (unisex race that develops temporary male or female reproductive functions depending on environmental and emotional stimulation); M. PIERCY, WOMAN ON THE EDGE OF TIME 105 (1976) (gestation takes place outside human body and breastfeeding is performed by either female parent or male parent with hormone treatment).

145. 417 U.S. 484 (1974).

146. 429 U.S. 125 (1976).

147. In Geduldig, a state disability plan that paid benefits to workers unable to work for any reason except normal pregnancy was challenged as violating women's right to equal protection under the Constitution. In General Electric, an employee insurance plan that covered all medical conditions except normal pregnancy was challenged under Title VII, the federal Equal Employment Opportunity law. See 42 U.S.C. $\S 2000$ e-2(a) (1982). 
opinions was the unarticulated assumption that pregnancy was a real difference, and that equality was therefore simply inapplicable. As Justice Stewart stated in Geduldig, "There is no risk from which men are protected and women are not. Likewise, there is no risk from which women are protected and men are not." 148

The Court's equality analysis could thus deal with overbroad generalizations, questions of closeness of fit, and even temporary affirmative action, but a generalization of difference between the sexes that was accurate, and permanently so, was beyond the pale. The first strand of the feminist critique of equality addresses this failing, asserting that equality analysis defines as beyond its scope precisely those issues that women find crucial to their concrete experience as women. ${ }^{149}$

Legal equality analysis "runs out" when it encounters "real" difference, and only becomes available if and when the difference is analogized to some experience men can have too. Legislative overruling of Gilbert by the Pregnancy Discrimination Act was thus accomplished by making pregnancy look similar to something men experienced as well-disability. ${ }^{150}$ Given the way employment is structured, pregnancy renders a woman unable to work for a few days to a few months, just like illness and injury do for men. ${ }^{151}$ However, what makes pregnancy a disability rather than, say, an additional ability, is the structure of work, not reproduction. Normal pregnancy may make a woman unable to "work" for days, weeks or months, but it also makes her able to reproduce. From whose viewpoint is the work that she cannot do "work," and the work that she is doing not work? ${ }^{152}$ Certainly not from hers.

Thus, the second strand of the feminist critique of equality states: Difference, which is created by the relationship of women to particular and contingent social structures, is taken as natural (that is, unchangeable and inherent), and it is located solely in the woman herself. It is not impossible to imagine a definition of "work" that includes the "labor" of childbirth; nor is it impossible to imagine a workplace setting in which

148. 417 U.S. at $496-97$.

149. On the importance of pregnancy and childbirth, see N. CHODOROW, THE REPRoductioN of Mothering (1978); S. Firestone, The Dialectic of SeX: The CaSe for Feminist REvolurion 81-118 (1970) (central to women's experience of oppression); N. CHODOROW, Family Structure and Feminine Personality in WOMAN, CULTURE AND SocIETY (1974) (central to women's experience of themselves as women). Other crucial issues of women's experience, such as rape, have also been defined as beyond equality's jurisdiction. See MacKinnon, Toward Feminist Jurisprudence, supra note 117 , at 635 .

150. See supra notes 104-15 and accompanying text.

151. Of course, women experience normal disability as well, but what is significant is that the analogy to men's experience was necessary to secure this right for women. See supra note 109 and accompanying text (discussing the PDA).

152. Social scientists have long understood that the definition of what counts as "work" is socially determined. See, e.g., WOMEN WORKING: ThEORIES AND FACTS IN PERSPECTIVE xiii-xvi (A. Stromberg \& S. Harkess eds. 1978). 
pregnancy would not be disabling. ${ }^{153}$

Analogizing pregnancy to disability has created new difficulties for a legal system trying to apply an assimilationist model of equality. In California Federal Savings \& Loan Association v. Guerra, ${ }^{154}$ an employer challenged a mandatory pregnancy leave statute, arguing that the law could be regarded as equal treatment, rather than a special bonus for women, only where men already have a right to disability leave for other reasons. Underlying the employer's argument was the assumption that the workplace is itself a gender-neutral institution that must treat all workers evenhandedly. Evenhanded treatment requires treating each worker the same as her coworkers, which means extending leave to all workers regardless of cause or denying leave to all. This reasoning falls prey to the second strand of the critique by assuming that if women have other needs for disability leave, it is because they are different.

It also gives rise to a third objection: that an institution structured so that women are inevitably disadvantaged by its facially neutral policies is itself phallocentric. Thus, the third strand of the critique challenges the assumed gender-neutrality of social institutions, as well as the notion that practices must distinguish themselves from "business as usual" in order to be seen as unequal. ${ }^{155}$

The inability of traditional equality analysis to cope with difference is not limited to biological differences in the workplace. Purporting to follow state constitutional equal rights amendments, many state courts have visited severe hardship on women in marital dissolution proceedings. In case after case, women who have spent most of the marriage as full-time homemakers and mothers are treated as "equal" to their male partners who have spent those years developing a career. ${ }^{156}$ In setting alimony awards, courts have refused even to consider the possibility that the woman might find herself at a competitive disadvantage in the job market-a disadvantage directly related to the work she performed during the marriage. Instead, the parties are treated "equally," and any

153. Obviously, the movement of the workplace from the home to the plant or office, see Rifkin, supra note 3, at 92-94, contributes to the conception of childbearing (as well as childrearing and domestic labor) as "not work." The need to search for other (male) conditions with which to analogize "women's differences" distracts us from criticizing the social structure in which the difference is created. (Krieger \& Cooney go so far as to suggest that the search is doomed in any event. See supra note 40, at 539-44.) Diane Polan thus criticizes acceptance of "equality" discourse as limiting women's ability to challenge broader forms of what she refers to as male supremacism. See Polan, supra note 3 , at 300.

154. 107 S. Ct. 683 (1987). See supra notes 104-15 and accompanying text.

155. Cf. Note, Complex Enforcement: Unconstitutional Prison Conditions, 94 HARv. L. Rev. 626, 628-30 (1981) (criticizing doctrines limiting eighth amendment violations to discrete aetions that "stand out" from the "background" of routine cruelty).

156. Such "equality with a vengeance" has been exhaustively documented by Lenore Weitzman, a sociologist who spent several years studying the concrete effects of California's adoption of "no fault" divorce. L. Weitzman, The Divorce Revolution (1985). 
prior disadvantaging of the woman vis-a-vis the workplace is completely ignored. ${ }^{157}$

To summarize, from a feminist viewpoint, current equality analysis is phallocentrically biased in three respects: (1) it is inapplicable once it encounters "real" difference; (2) it locates difference in women, rather than in relationships; and (3) it fails to question the assumptions that social institutions are gender-neutral, and that women and men are therefore similarly related to those institutions. What the three strands of this critique share is their focus on "difference." A reconstructed equality analysis-one that seeks to eliminate, or at least reduce, the phallocentrism of the current model-must at some point deal with each strand of the critique. Thus, from a theoretical standpoint, symmetrical equahty models, with their insistence that difference be ignored, eradicated or dissolved, are not responsive to the feminist critique of equality.

\section{B. Illustrations of the Feminist Critique}

\section{Construction of Sex: "Male" and "Female" as Social Categories.}

Several theorists have asserted that the existence of transsexuality demonstrates that sex is a social, not a biological, category. ${ }^{158}$ I want to claim that it is both, and that this double categorization contributes substantially to the confusion and complexity that surrounds sexual equality analysis.

At this point, a few concrete examples of the "socially male/socially female" concept may be useful, and will serve to demonstrate the importance of distinguishing between biological sex and social sex. Consider the plight of the male plaintiff in Spaulding $v$. University of Washington, ${ }^{159}$ a case in which the predominantly female nursing department faculty at the University of Washington complained that they were being discriminated against because their pay scales were much lower than pay scales in other (predominantly male) departments. While most of the plaintiff class were women, one member was a male nursing professor.

157. Weitzman's findings indicate that one year after divorce, the standard of living of male exspouses rises $43 \%$, while the standard of living of female ex-spouses falls $73 \%$. Weitzman, The Economics of Divorce: Social and Economic Consequences of Property, Alimony, and Child Support. 28 UCLA L. REV. 1181, 1251 (1980). She blames this economic disaster not on the concept of "no fault" divorce itself, but on the state legislature's failure to take into account that male and female partners to marriage usually stand in asymmetrical positions with respect to the job market. Sec Stix, Disasters of the No-Fault Divorce, L.A. Times, Nov. 7, 1985, $\S$ V, at 3, col. 1.

158. See Wasserstrom, supra note 52, at 587; see also C. MacKinnon, Pleasure Under Patriarchy: The Feminist/Political Approach to Sexuality 3 n.8 (forthcoming in THEORIES AND Paradigms of Human Sexuality (J. Gier \& W. O'Donahue eds.)) ("That men are born into and assigned masculinity on the basis of the biology of sex does not make gender biological. . . . [Q]ualities and behaviors of maleness, hence men (as are those of femaleness and women) are social and political, and subject to accountability and change as such.").

159. 740 F.2d 686 (9th Cir.), cert. denied, 469 U.S. 1036 (1984). 
The Ninth Circuit found that the district court had erred in not dismissing the poor guy from the suit. The following exchange paraphrases the appellate court's discussion:

Male nurse: Equality!

Court: You can't argue equality; you're being treated just like the other nursing professors are.

Male nurse: Wait a minute. Nursing professors are paid less because nursing is a female occupation, and nursing professors tend to be women. Court: So let them argue that. You can't argue that you're paid less "because" you're a woman since you aren't a woman, and you can't argue that you're paid less "because" you're a man since that's not why you're paid less. ${ }^{160}$

Actually, what the male plaintiff was complaining about was that he was being paid less on the basis of his sociological sex, not his biological one.

The D.C. District Court had a very different response in Hopkins v. Price Waterhouse. ${ }^{161}$ In that case, a female plaintiff had been denied partnership in a major accountimg firm in part because she was not considered feminine enough. ${ }^{162}$ Although her language and "tough personality" were similar to that of inany of her male colleagues, many partners found these characteristics offensive in a woman. The court had no difficulty in finding sex discrimination, characterizing the partners' responses as stereotyping. ${ }^{163}$

Spaulding illustrates both that biological males may engage in socially fernale behavior, and that such "social transvestitism" appears to confuse judges. Hopkins, on the other hand, presents a biological female engaging in socially inale behavior, a phenomenon that appears to inake more sense to judges. In a legal system with an assimilationist approach to equality, it is hardly surprising that the right of a woman to be socially male should be understood and affirmed while the claim of a socially female man is met with bafflement.

\section{Construction of Equality}

Feminist critiques of equality have been anbivalent about whether the phallocentric bias in equality is inherent, or is simply its current content and therefore alterable. ${ }^{164} \mathrm{I}$ am convinced that both the ineaning of

160. Id. at 709 .

161. 618 F. Supp. 1109 (D.D.C. 1985).

162. When plaintiff consulted with the head partner at OGS, who was her strongest supporter and responsible for telling her what problems the Policy Board had identified with her candidacy, she was advised to walk more femininely, talk more femininely, dress more femininely, wear make-up, have her hair styled, and wear jewelry.

Id. at 1117 (footnote omitted).

163. Id. at 1118. Attributing the stereotyping of individual partners to the firm as a whole required the additional analytical step of finding a sex-biased process.

164. I take Janet Rifkin and Diane Polan's critiques as at least suggesting that equality is hopelessly flawed and should be jettisoned. See Rifkin, supra note 3; Polan, supra note 3; cf. Olsen, 
sex and the meaning of equality are socially constructed, and that they can be socially reconstructed from the ashes left by feminist critique. ${ }^{165}$

The mathematical fallacy - that equal must mean similar-is one problem with the current concept of equality. Nevertheless, this would not be so severe a problem for women (and for those men socially classed as women) were it not for the phallocentric fallacy that consistently leads courts (and even legal reformers ${ }^{166}$ ) to choose the (biological or social) male as the norm and to locate difference in the female. The critique of equality as phallocentric has led some feminist legal theorists to reject the concept of equality and argue that women should demand something else-perhaps justice, perhaps special rights based on special needs. ${ }^{167}$ It has led others to reject the critique itself and continue to promote the similarity of women to men in the name of equality. Neither reaction, however, escapes the phallocentrism of the culture.

Consider the woman who recently lunched in the restaurant of the Beverly Rodeo Hotel. ${ }^{168}$ When she began breastfeeding her infant the manager asked her to leave the dining room. What routes are open to her? Imagine the following dialogue:

Woman: Equality!

Restaurant: Yes, let's have equality. We don't allow men to bare their breasts in the dining room, so we can't let you do it either. (Assumption of symmetry.)

Woman: Wait a minute. There's a difference between those two situations.

Restaurant: Yes, there's a difference. Women's breasts are far more disruptive than men's breasts. Keep yours covered. (Location of difference in the woman.)

Woman: No, I have different needs and this social institution should take account of them.

Restaurant: Fine, go over there behind that screen. You can rejoin the

Statutory Rape: A Feminist Critique of Rights Analysis, 63 TEx. L. REV. 387, 430 (1984) (suggesting women might get further by asking for what they want rather than for what rights discourse constrains them to request).

165. While this position could be read as "anti-essentialist" in the terms of the French feminist debate, see T. MoI, supra note 91, at 12-15 (1985), my current thinking is agnostic about whether there is an essential "femininity beyond deconstruction." See Schorr, supra note 91, at 7.

166. Note, however, that legal reformers often have little choice in these matters. Surely the drafters of the Pregnancy Discrimination Act chose to analogize pregnancy to disability because Title VII's singular focus on the workplace constrained them from recognizing women's rights beyond the employment sphere-i.e., their procreative rights. That California's Fair Employment and Housing Act does recognize an affirmative right to job-protected pregnancy disability leave demonstrates that an alternative was available, but whether affirmative steps could have been enacted at the national level is unclear.

167. This is, of course, one form of the symmetrical vs. asymmetrical debate. See supra text accompanying notes 75-122.

168. Kaufman v. Beverly Rodeo Hotel, No. C494133 (Cal. Super. Ct. Santa Monica, filed April 12, 1984). 
others when you're finished. ("Accommodation" of difference leaves institution itself as rejecting the woman.)

The significance of restrictions on breastfeeding is often obscured by classifying them as mere "clothing regulations." While I reject the notion that clothing regulations are in fact trivial, ${ }^{169}$ it is more important here to recognize the difference between requiring patrons to wear shoes, shirts, ties, or skirts in public accommodations and applying such requirements to the baring of a female breast during lactation. To illustrate this difference, we might examine two attempts to analogize restrictions on breastfeeding and restrictions on attire.

First, consider the requirement of formal dinner attire in particular restaurants. Any man or woman might find such clothing regulations burdensome at one time or another, but such rules generally do not carry with them a concomitant restriction on actions that are of crucial significance to the person and that cannot easily be delayed. Waiting until after dinner to change into my jeans may restrict some actions (sitting cross-legged, for instance), but it does not cause significant distress; waiting to feed a hungry infant could easily distress others, as well as myself. In addition, the act of breastfeeding has both personal and social significance to women far beyond questions of comfort or mobility.

A second hine of analogy is suggested by the example itself. Bodily parts that are culturally associated with sexual intercourse are usually required to be covered during social intercourse. This custom may justify prohibitions on topless bathing costumes or the like; however, to maintain it with respect to breastfeeding is to view women's breasts solely from the male perspective-as sexual signals or erogenous zones. ${ }^{170} \mathrm{~A}$ woman involved in the breastfeeding of her infant is engaged in an activity at least partially removed from male control over the use of her breasts. The connection is between her and her infant, not between her and the man or men who happen to be watching. To this extent, the male view of a bared breast is largely irrelevant to the female perspective on breastfeeding. ${ }^{171}$ To use the former perspective and ignore the latter is to choose phallocentrism over equality.

169. For an excellent analysis of the role that clothing regulation plays in a patriarchal social order, see Whisner, Gender-Specific Clothing Regulation: A Study in Patriarchy, 5 HARv. WoMEN's L.J. 73 (1982). Cf. Goldman v. Weinberger, 106 S. Ct. 1310 (1986) (rejecting plaintiff's asserted first amendment right to wear yarmulke in military service).

170. Of course, it is not at all unusual for women, and especially women's body parts, to be viewed exclusively from men's perspective. See Whisner, supra note 169, at 109-14; see also A. DWORKIN, PORNOGRAPHY, supra note 117 , at $45-47$.

171. I am grateful to my colleague Carole Goldberg-Ambrose for pointing out the possibility of a closer analogy between religious identity and sexual identity in this context. The significance women place on breastfeeding might be compared to the significance an orthodox Jew places on Kosher food. There is a way in which the ubiquity of certain foods (cheeseburgers, seafood etc.) in American cuisine signals the "otherness" of Jewishness similar to the signal sent to lactating women. 


\section{Equality as Acceptance}

The model of equality as acceptance responds to the first strand of the feminist critique of equality by insisting that equality can in fact be applied across difference. It is not, however, a "leveling" proposal. Rather, equality as acceptance calls for equalization across only those differences that the culture has encoded as gendered complements. The theory of comparable worth provides one example of this, and the field of athletics yields another.

Most proponents of comparable worth have defined the claim along the following lines: jobs that call for equally valuable skills, effort, and responsibility should be paid equally, even though they occur in different combinations of predominantly female and predominantly male occupations. ${ }^{172}$ Thus, when an employer has defined two job classifications as gendered complements, the employer should pay the same to each. Equality as acceptance makes the broader claim that all behavioral forms that the culture (not just the employer) has encoded as "male" and "female" counterparts should be equally rewarded. ${ }^{173}$ Acceptance would thus support challenges to the overvaluation of "male" skills (and corresponding undervaluation of "female" ones) by employers, rather than limiting challenges to unequal application of an existing valuation ${ }^{174}$ or to the failure to make such a valuation. ${ }^{175}$

In the sphere of athletics, equality as acceptance would support an argument that equal resources be allocated to male and female sports programs regardless of whether the sports themselves are "similar."176 In this way, women's equality in athletics would not depend on the ability of individual women to assimilate themselves to the particular sports activities traditionally engaged in by men. ${ }^{177}$

Under the model of equality as acceptance, equality analysis does not end at the discovery of a "real" difference. Rather, it attempts to

172. Note, Comparable Worth-A Necessary Vehicle for Pay Equity. 68 MARQ. L. REv. 93, 98 n.33 (1984). See generally COMMitTEe ON OCCUPATIONAL Classification \& ANALYSIS, ASSEmbly of Behavioral \& Social Sciences Nat'l Research Council, Women, Work, AND WAGES: EQUal PAY For JobS OF Equal VALUe (1981).

173. Some of the complexities of this determination are explored infra, Part IV.

174. The Supreme Court accepted the proposition that intentional unequal application would violate Title VII in County of Washington v. Gunther, 452 U.S. 161 (1981).

175. Thus far, courts have not been eager to find a violation in the failure to make evaluations. Cf. cases cited in Note, supra note 26, at 490-91 n.22.

176. Compare A. Liebman, Model Regulations Handbook: A Guide to Implementing THE SEEA AND TITLE IX (1984) (suggesting a quasi-acceptance model to implement the California Sex Equity in Education Act) with Brenden v. Independent School Dist. 742, 477 F.2d 1292 (8th Cir. 1973) (assimilationist model).

177. For a more detailed critique of athletics cases, see Littleton, Equality Across Difference, supra note 37. 
assess the "cultural meaning"178 of that difference, and to determine how to achieve equality despite it. This formulation responds to the second strand of the feminist critique by locating difference in the relationship between women and men rather than in women alone, as accommodation arguably does. Acceptance would thus provide little support for the clain that traditionally male sports (such as football) sliould be modified so as to accominodate woinen (or vice versa). Equality as acceptance does not prescribe the superiority of socially female categories, nor even the superiority of androgynous categories. It does, however, affirm the equal validity of men's and women's lives.

Finally, equality as acceptance responds to the third strand of the feininist critique by acknowledging that women and men frequently stand in asyınmetrical positions to a particular social institution. It recognizes that woinen are frequently disadvantaged by facially neutral practices and insists that such asymmetries be reflected in resource allocation. To carry forward the athletics example, equality as acceptance would support an equal division of resources between male and feinale programs rather than dividing up the available sports budget per capita. Since women and men do not stand symmetrically to the social institution of athletics, per capita distribution would simply serve to perpetuate the asyminetry, diverting more resources to male programs, where the participation rate lias traditionally been higli, and away froin female programs, where the participation rate has been depressed both by women's exclusion from certain sports and by the subordination of those activities women have developed for theinselves.

It may be apparent froin the preceding paragraphs that equal acceptance as a legal norm does not automatically produce one and only one "riglit answer" to difficult questions of equality. Instead, it provides support for new remedial strategies as well as a method of uncovering deeper layers of inequality. ${ }^{179}$

\section{Acceptance, Not Accommodation}

Asymmetrical equality theorists have usually been taken to mean that male institutions should take account of women's differences by accoinınodating those differences. ${ }^{180}$ "Reasonable accommodation" can

178. Cf. Lawrence, The Id, the Ego, and Equal Proteetion: Reckoning with Unconscious Racism, 39 STAN. L. REV. 317, 355-62 (1987) (discussed in text accompanying note 286).

179. For a discussion of how these examples illustrate the relationship among various feminist theories of inequality, see Littleton, Equality and Feminist Legal Theory, 48 U. PITT. L. REV. 1043 (1987).

180. See, e.g.. E. WolgaST, supra note 93; Krieger \& Cooney, supra note 40; Scales, supra note 40, at 435-37. The legal system has thus far implemented a limited form of accommodation in two contexts: first, for the physically or mentally disabled, as a duty placed on public facilities to provide access, or on employers to take reasonable steps to allow physically and mentally challenged workers 
be asked of a court (although the people usually being asked to be "reasonable" are those asking for accommodation), and if the choice truly is between accommodation and nothing, "half a loaf" is better than none. ${ }^{181}$

The problem with accommodation, however, is that it implicitly accepts the prevailing norm as generally legitimate, even as it urges that "special circumstances" make the norm inappropriate for the particular individual or class seeking accommodation. ${ }^{182}$ In addition, it falls prey to the feminist critique of equality by labeling women as deviant from the norm, thus locating the difference in women. Assimilated women are particularly vulnerable to this misperception, and are all too often persuaded to drop valid demands for inclusion on their own terms by the response that they are asking for "an exception."183

The distinction between accommodation and acceptance may be illustrated by a rather commonplace example. I remember a feminist lawyer walking up to a podium to deliver a speech. The podium was high enough that she could not reach the microphone. While arrangements were being modified, she pointedly noted, "Built for a manl" Accommodation is a step platform brought for her to stand on. Acceptance is a podium whose height is adjustable.

III

\section{DifferenCE AND THE SYSTEM OF "MALE" POWER}

The model of equality as acceptance attempts to be responsive both to the feminist critique of equality (as phallocentric) and to the feminist critique of society (as male-dominated). This Part addresses the latter by describing the double nature of male dominance that results in both oppression and subordination of women, and by showing how equality as acceptance responds to this second feminist critique.

\section{A. Oppression and Subordination}

Marilyn Frye uses the metaphor of a birdcage to explain the difference between individual acts of oppression, which may be perpetrated

\footnotetext{
to perform already existing jobs; second, for women and racial minorities, as a partial and fragile duty placed on public officials and employers to engage in "affirmative action" designed to remedy prior discrimination.

181. But see Williams, supra note 2, at 380 (arguing that the attraction of piecemeal solutions is illusory).

182. It is, I think, the assumption that all asymmetrical equality theorists advocate accommodation that leads symmetrists to accuse us of asking for "special treatment" rather than "equal treatment."

183. It is invalidating, on some deep level, to be treated as an exception, and asking for an accommodation under current conditions is asking for an exception. Not only do such requests fail to challenge the "rule," but they often stick in our throats.
} 
against members of either sex, and the systematic oppression that allows us to refer to one sex as an "oppressed class."

Consider a birdcage. If you look very closely at just one wire in the cage, you cannot see the other wires. ... [E]ven if, one day at a time, you myopically inspected each wire, you still could not see why a bird would have trouble going past the wires to get anywhere. There is no physical property of any one wire, nothing that the closest scrutiny could discover, that will reveal how a bird could be inhibited or harmed by it except in the most accidental way. It is only when you step back, stop looking at the wires one by one, microscopically, and take a macroscopic view of the whole cage, that you can see why the bird does not go anywhere . . . 184

Frye's metaphor does capture the nature of systematic oppression, but fails to capture the nature of systemic subordination. While it is true that women are systematically oppressed, it is nonetheless also true that "the female," a "social" category that often overlaps the biological category of women, is systemically subordimated.

Sex as a social category carries the social meaning of what might otherwise be an empirical designation of anatomy, ${ }^{185}$ and this conflation of empirical designation with social meaning infringes the liberty of both women and men. ${ }^{186}$ The weight of the infringement, however, is not necessarily symmetrical. For example, consider the range of acceptable male body size as compared with the range of acceptable female body size; ${ }^{187}$ consider also Bem and Bem's point that predictions of women's primary occupations are much easier to make than predictions of men's primary occupations. ${ }^{188}$ It is true that both women and men are constrained by an acceptable range, but that range is significantly different for the two sexes. ${ }^{189}$ In this sense, Frye's use of the term "oppression" is appropriate.

The root of the word 'oppression' is the element 'press.' . . . Presses are used to mold things or flatten them or reduce them in bulk . . . .

184. M. FRYE, supra note 92, at 4-5.

185. See supra notes $158-63$ and accompanying text.

186. In this respect, Dru Cornell's "equality of freedom" proposal appears to be symmetrical, although at a very different level than mainstream sex equality analysis. See D. Cornell, Equality and Gender Difference: Towards a Critical Theory of Equality (1983) (unpublished manuscript on file with the author) (men and women must have equal freedom to "opt out" of culturally male and culturally female stereotypes).

187. See, e.g., K. Chernin, The Obsession: Reflections on the Tyranny of SLENDERNESS 122 (1981).

188. Bem \& Bem, Homogenizing the American Woman: The Power of an Unconscious Ideology, in FEMINIST FRAMEwORKS 6, 6-8 (1978).

189. Occasionally, mainstream equality analysis recognizes this fact. See, e.g., Gerdom v. Continental Airlines, 692 F.2d 602 (9th Cir. 1982), cert. dismissed, 460 U.S. 1074 (1983) (holding an airline's strict weight limitations for female-only job classification of "stewardess" sex discrimination because more onerous to women); $c f$. Whisner, supra note 169, at 94-97 (shorter hair requirements for men reinforce theory of gender differentiation, which supports the continued subordination of women). 
Something pressed is something caught between or among forces and barriers which are so related to each other that jointly they restrain, restrict or prevent the thing's motion or mobility. Mold. Immobilize. Reduce. ${ }^{190}$

The inequality of women in their lived-out experience, however, is not limited to the relatively greater constraints on their liberty to "opt out" of their assigned sex role. Rather, there is a more direct equality interest at stake: full membership, belonging, and participation-acceptance as full human beings. This equality interest is infringed by having everything that is associated with women defined as less valuable, less necessary to consider, less important.

To illustrate, im Corning Glass Works v. Brennan, ${ }^{191}$ an early case involving the Equal Pay Act, ${ }^{192}$ the Supreme Court upheld a challenge to an employer's practice of setting higher pay rates for night-shift inspectors than for day-shift ones. At the time the night shift was instituted, women were prohibited by state law from working at night, but the higher rates were continued beyond the introduction of women into the might shift. The Court noted in passing that "[t]here is also some evidence in the record that additional compensation was necessary because the men viewed inspection jobs as 'demeaning' and as 'women's work." "193 There is no indication in the case that the work was "demeaning" for any reason other than that it was "women's work." In a similar vein, the job of "secretary" was, when performed almost exclusively by men, one of high status as well as a primary route into management. When the job became female-dominated, it somehow lost status, relative pay, and upward mobility. ${ }^{194}$ Anthropologists spent decades trying to fit our knowledge of human evolution into a pattern of the needs of "man the hunter" 195 without even considering the needs of "woman the gatherer"196 or "woman the childrearer,"197 much less the needs of

190. M. FRYE, supra note 92, at 2; see also Taub, Keeping Women in Their Place: Stereotyping Per Se as a Form of Employment Discrimination, 21 B.C.L. REV. 345 (1980).

191. 417 U.S. 188 (1974).

192. The Equal Pay Act provides in relevant part:

No employer having employees subject to [the Act] shall discriminate, within any establishment in which such employees are employed, between employees on the basis of sex by paying wages to employees in such establishment at a rate less than the rate at which he pays wages to employees of the opposite sex in such establishment for equal work on jobs the performance of which requires equal skill, effort, and responsibility, and which are performed under similar working conditions ....

29 U.S.C. $\$ 206(d)(1)$ (1982).

193. Brentnan, 417 U.S. at 191-92 n.3.

194. See S. Rothman, Woman's Proper Place 48-52 (1978).

195. See, e.g., D. MORRIS, THE NAKED APE (1967) (explaining human evolution from the perspective of male "hunter").

196. See sources discussed in S. HARDING, supra note 5, at 95-100.

197. See E. Morgan, The Descent of Woman (1972) (suggesting that Desmond Morris ignored other available theories of human evolution). 
"woman for herself."

We can read such examples as simply more evidence that oppression and subordination are systematic - that is, that they occur with such frequency as to become almost invisible. But the feminist critique of male power does not stop there. Rather, it questions whether in addition male power is systemic. This question is explored below.

\section{B. Male Power as a System}

How can feminism speak of "male" power in the face of countless examples of men lacking power-the soldier who does not choose his target, the assembly-line worker who does not control the product of his labor, the father who does not choose his absence from his children's lives, the lover who does not choose the image in his head that makes him so critical of his mate's shortcomings? Even if male doininance operates in the interest of all men, ${ }^{198}$ it certamly does not operate equally for all men. ${ }^{199}$ While some forms of male power (such as the ability to physically or psychologically intimidate women) is shared broadly, other forms (such as the ability to deny women access to certain jobs and careers) are more narrowly concentrated. ${ }^{200}$

Feminist critique argues that individual or class differences among men in the degree of power they hold over women are not directly relevant to the issue of male power as a system. Rather, the form of male power that constructs male dominance as a social system rather than as a systematic assertion of dominance by particular men can be viewed as concentrated in the hands of a few men who are at or near the top of intersecting hierarchies of sex, race, and class, reserved to those in what I

198. See, e.g., Peterson, Coercion and Rape: The State as a Male Protection Racket, in M. Vetterling-Braggin, F. Ellison \& J. English, Feminism and Philosophy 360-71 (1977).

199. See, e.g., A. DAVIS, supra note 46, at 172-201 (myth of the Black rapist constructed to oppress Black men).

200. Nor does male power operate equally on all women. Women comprise a class, but they are also members of every racial and social class. Therefore, sexual "equality" on male terms means different things to us. Even if granted, it would only allow Black women to share the status already available to Black men. Similarly, racial "equality" would make Black women "equal" to white women, not to some genderless class of "whites." The same holds true for class. The feminist critique of equality as phallocentric is not the only critique of equality as itself unequal. See, e.g., Freeman, Antidiscrimination Law: A Critical Review, in THE Politics of LAw 96-97, 116 (D. Kairys ed. 1982) (criticizing antidiscrimination law as "rationaliz[ing] the continued presence of racial discrimination in our society"); Lawrence, supra note 178 , at $358-62$ (criticizing inability of current equal protection doctrine to address "unconscious racism").

And yet, there is in all critiques of equality doctrine a common theme of failure to deal with difference. To the extent, then, that feminist critique takes difference as its focus, to the extent it claims that the "view from the margin" has validity, and to the extent that feminist legal theory remains faithful to that critique, sexual equality doctrine may develop its own generative quality. Other forms of subordination may become visible to the culture through the lens of sexual equality doctrine, just as some forms of the subordination of women became visible through the lens of racial equality doctrine. 
will call "the club."201 The constitutive form of male power exercised by the club is the power to set the terms by which all forms of human activity are given social meaning and social value. ${ }^{202}$ The power to define what is and is not a right, a legal interest, equality, justice, or law itself, is power that constitutes a system. It is the power to construct reality itself; it is the power to "speak the world." 203

This club is "male" not because of some biological essence that only men possess. Institutions created from the socially male perspective do not depend on biological males to sustain them. It is true that the apparent intractability of male institutions (especially the institution of rape) ${ }^{204}$ gives rise to some feminist suspicion as to their contingency, and thus leads some to posit a necessary link between biological sex and social sex. ${ }^{205}$ However, at least in this Article, I am concerned with maleness in the cultural and not the biological sense.

I identify the power exercised by the club as male power, as opposed to power per se, for two reasons. First, as I have argued in this Article, and as numerous other feminists have demonstrated in the work on which I have drawn, the power of the club operates against individual women to a greater extent than against individual men. Even if no account is taken of the way in which the socially female is devalued, that biological women are significantly deprived economically might lead one to suspect that it is not female power that is at work here.

Second, feminist scholars have demonstrated distinct differences between the ways in which women and men may conceive of and exercise

201. The "club" metaphor, while powerful, is not perfect. It fails to capture the way in which particular people might be "club members" in some ways but not in others. For example, white women could be seen as club members with respect to race, although somewhat suspect club members, given white women's occasional ability to glimpse other forms of oppression and subordination through the particular lens of our own.

It is also the case, however, that a club functions in many ways apart from its individual members, so that whether or not a majority of the members of the Bohemian Club are sexist (to name one notorious all-male executive club in California), the clubs themselves retain a sexist infiuence almost independent of their members' orientation.

202. See D. SPENDER, supra note 10 , at 76 (" $[t]$ he models-the meanings/theories/structureswhich exist have been formulated by males and they have been validated with reference to other males. Stating it simply, men have made up the meanings for society and then have checked with other men to see if those meanings are accurate.").

203. In Genesis, the story runs that God gave Adam the right to name all of the animals and plants. See M. DALY, BEYOND GOD THE FATHER 8 (1973) (women "have had the power of naming stolen from us"); D. SPENDER, supra note 10, at 165-71.

204. Rape ceases to be an individual act and becomes an institution at the point that the freedom of all women is restricted and controlled by its prevalence. Sec, e.g., S. BrownmlLer, AGAINST OUR WILL (1975). "From prehistoric times to the present, I believe, rape has played a critical function. It is nothing more or less than a conscious process of intimidation by which all men keep all women in a state of fear." Id. at 15 (emphasis in original).

205. See, e.g., Penelope, The Mystery of Lesbians, Part I, 1 LesBian ETHICs 7, 17-18 \& n.7 (1984). 
"power" itself. Carol Gilligan's germinal ${ }^{206}$ work In a Different Voice has given a vocabulary to previously unarticulated nuances in women's use of the term "power." "[W]hile men represent powerful activity as assertion and aggression, women in contrast portray acts of nurturance as acts of strength."207 While again noting that male-female differences in this area are matters of degree rather than absolutes, the way in which an apparently neutral term such as "power" takes on gendered ambiguity on close analysis is instructive. In referring to the power that sets the terms and limits of social valuation as "male power," I mean to refer to power as control over others, as opposed to power as ability to help. To call the former male and the latter female is not to say that women are never controlling or that men are never interested in helping; rather, it is to recognize the ways in which social typing both reflects and helps to shape statistical tendencies.

The club, then, exercises male power to the extent that it defines for others what is to be aspired to, rather than helping others to articulate aspirations or to achieve the aspirations so articulated. The perceived privileges of membership in the club ${ }^{208}$ consist in the ability to see one's actions mirrored in the world-to have one's point of view accepted, not as a point of view, but as simple reality. ${ }^{209}$ For example, until Gilligan's critique emerged, ${ }^{210}$ Kohlberg's theory of moral development was viewed not just as a model of the moral development of adolescent males, but as the way all people developed morally. In this system, women appeared to be stunted, "inexplicably" stuck at the lower stages of Kohlberg's hierarchy. Likewise, Catharine MacKinnon's work on rape points out the way in which rape law's ostensibly neutral inquiry into objective factWas it rape? - can be viewed as reflecting only the male actor's perspective. "When the reality is split-a woman is raped [her experience] but not by a rapist [his experience] - the law tends to conclude that a rape did not happen." ${ }^{211}$ His experience becomes truth. ${ }^{212}$

206. I use the term "germinal" in place of the more usual "seminal" both to counter male bias (why is semen more like seed than ova are?) and because the notion of "germination" seems closer to what is being honored in works so described.

207. C. GllligaN, supra note 11, at 167-68 (discussing David McClelland's work on the different ways men and women tend to fantasize power).

208. I say "perceived" privileges because some white upward men tell me, and I believe them, that they feel deprived of some aspect of their humanity by the process of joining and maintaining membership in this club. However, very few of those same men let their memberships lapse.

209. "Representation of the world, like the world itself, is the work of men; they describe it from their own point of view, which they confuse with absolute truth." MacKinnon, An Agenda for Theory, supra note 23, at 537 (quoting S. DE BEAUvoIR, supra note 35). On the relation between gender and epistemology, see Held, Feminism and Epistemology: Recent Work on the Connection between Gender and Knowledge, 15 PHIL. \& PUB. AFF. 296 (1986); on the relation among gender, power and epistemology, see MacKinnon, Toward Feminist Jurisprudence, supra note 117, at 635-45.

210. See supra notes 11-13 and accompanying text.

211. MacKinnon, Toward Feminist Jurisprudence, supra note 117, at 654 . 
Club members themselves are not free from the system their words, actions, hopes, and fears create. They may "speak the world," but the world thus spoken has negative consequences for the speaker as well. ${ }^{213}$ Nevertheless, the power thus to speak is apparently hard to give up. Moreover, in response to challenges to its power, the club is more likely to extend the illusion of possible membership than to abandon its practices. ${ }^{214}$ The terms of such admission are simple: "outsiders" may join the club one at a time, in the same way that Boy Scouts become Eagle Scouts, by earning the right number and combination of merit badges.

Women who are "privileged" in racial and class terms seem more vulnerable to the false promise of individual acceptance into the club, probably because the promise is held up so tantalizingly close. "We're just like you," we have shouted at the clubhouse doors. "Look at our merit badges: we've gone to your schools, learned your language, copied your work styles. Let us in." And our badges got us in. ${ }^{215}$ However, the power we've earned as socially male clubmembers has not earned us the right to speak in our own voices. Our club membership is contingent on our willingness to either speak in a male voice or remain silent. ${ }^{216}$ And since speech as it is used by the club is the power to silence others, we must agree to use our voices to silence other women. ${ }^{217}$

212. Such power, even if not widely shared, is not limited to the "mainstream." At the CLS interim gathering (a.k.a. "summer camp") three years ago, a presentation and discussion session to explore the usefulness of sociological research to critical legal theory quickly turned into an intellectual scoring game. For the rest of the session, not one woman raised her hand to speak. As soon as the session was over, one of the leaders rushed over to me. "Why didn't the women talk?" he demanded. "We didn't try to exclude you." "We weren't interested in what you were doing," I replied. "That can't be true!" he expostulated. "We were doing social theory. You can't tell me you're not interested in social theory." The point is not that social theory was or was not being done; the point is that what most of the women experienced as a competition, most of the men experienced as "business as usual." To say, in effect, that women's refusal on this occasion to engage in the competition was a refusal to engage in social theory is to define social theory from the perspective of only half the group.

213. In the late 1960's, a spate of popular books appeared, lamenting the plight of men trapped in rigid sex roles. See, e.g., M. BRENTON, THE AMERICAN MALE S2-57 (1966) (discussing cultural restrictions on emotional display).

214. Cf. Schaar, Equality of Opportunity and Beyond, 9 Nomos 228, 230-31 (1967) (adherence to status quo masked by apparent progressivism of equality of opportunity); Freeman, supra note 200 , at 116 (illusion of equal opportunity legitimizes unequal conditions).

215. Or so we thought. No matter how much of our selves we tore out, the badges still read "almost male," or "like a man." We cannot perfectly conform; at some point our very bodies betray the deception. We are recognized as counterfeit men with counterfeit badges. Counterfeit badges get you counterfeit power-power to lip-synch, not power to speak.

216. A recent study of major law firms in Los Angeles, performed under the auspices of the Women Lawyers' Association of Los Angeles, found that only $4 \%$ of partners in such firms were women. See L.A. Daily Journal, Nov. 16, 1983, at 5, col. 1. Despite the success of women in matching male entry-level criteria, many of those women are passed over for partnership, or leave "voluntarily" before the decision is made.

217. Many of the essays in ThIS BRIDGe CALLED MY BACK, supra note 69, explore this issue from the point of view of radical women of color. See especially the section entitled And When You 
As women, neither option is "better" than the other. Power as it is wielded by the club is not the kind of power that women want for ourselves; it is male power. ${ }^{218}$ Thus, assimilation ultimately fails on two levels. As the plaintiff in Hopkins v. Price Waterhouse ${ }^{219}$ experienced, socially male women are always at risk of being "discovered" as biological women. And, as Kathryn Powers points out, the "success" of a few aspirational women justifies a system that excludes and subordinates most women. ${ }^{220}$ When those of us with culturally male credentials speak on behalf of all women, we walk the tightrope between losing our place in the male social world and silencing other woinen whose experiences differ from our own. . $^{221}$

This view of male power as a system may not be the only explanation for women's situation, but it is the one most plausible to me right now. It "fits" the observable data and provides some rationale for why "difference" is so troubling to current equality analysis. Differences in biology, moral reasoning, or social experience should result in inequality only if the society is concerned with maintaining the club. The perpetuation of that club requires the eradication of difference from candidates for membership before the granting of equality, so that those who enter the gates-be they biologically male, female, hermaphrodite, white, Black, brown, yellow, or red, and be they materially possessed of much or little-will enter as socially male, white, and upwardly mobile.

\section{Responding to the Critique of Male Power}

Theoretically, society could abolish the value hierarchy ordained by the club and replace it with a new hierarchy of human values. It could calculate new, unbiased values for primary education, childrearing, and housecleaning. It could, in the words of one of my colleagues, turn these questions into "social issues." However, while such ostensibly "neutral" revaluation has a great deal of surface appeal, it ignores the long-stand-

Leave, Take Your Pictures With You: Racism in the Women's Movement in id. at 63-101. Audre Lorde has also been angrily eloquent on the use of borrowed power to silence Black women, poor women, and lesbians. See generally A. LORDE, supra note 38.

218. See supra notes 206-12 and accompanying text.

219. 618 F. Supp. 1109 (D.D.C. 1985) (discussed supra notes 161-63 and accompanying text).

220. Powers, Sex Segregation and the Ambivalent Directions of Sex Discrimination Law, 1979 W1S. L. REV. 55, 91-93.

221. As Richard Delgado explores in The Imperial Scholar: Reflections on a Review of Civil Rights Literature, 132 U. PA. L. REV. 561 (1984), white male theorists fail to cite minority scholars when dealing with civil rights issues. He contrasts this to their tendency to cite at least some female legal scholars when writing about sex, although these female scholars are also white. Id. at 574 . This self-referencing system makes it particularly important that white feminists recognize our own position in social hierarchies, since without a recognition of, and struggle with, our own "white blindness," we will likely perpetuate this disability in the legal literature. 
ing devaluation of behaviors, concerns, and occupations associated with women.

Rethinking the social value of childrearing, for instance, without simultaneously revaluing all "women's work" could hardly avoid replicating much of the current skewed value hierarchy. Additionally, the construction, through public debate and struggle, of a new social value hierarchy must include the voices of those who have been unheard within traditional policy discourse, including social women. Without some separate strategy to include these voices, public debate will continue to be male, even though some of its participants will be biological women.

Alternatively, if I am right that the maintenance of the club depends on equality meaning sameness, then each reduction in inequality across difference will make the next step easier and more accessible to critique. Though it may take a long time, we can rescue equality and destroy the club by accepting difference, by making sex difference not make a difference in equality, by making difference "costless" (or at least cost less) in one context after another.

The model of equality as acceptance makes difference less costly by equalizing the resources "merited" 222 by gendered complements-that is, by related "male" and "female" attributes or actions. ${ }^{223}$ The choice of which resources to equalize is contingent, and has been made on pragmatic, rather than theoretical, grounds. For the present, the model will hold constant the coin in which gendered complements are to be measured-money, status, and access to decisionmaking.

These measures and their application are themselves subject to feminist critique. First, both the value of money and the meaning of status are artifacts of a phallocentric culture. ${ }^{224}$ Given the choice, women might choose to value things in nonmonetary form or to define status in a radically different way. Positing alternative currency, however, will have to await a time when women have equal access to the mint. ${ }^{225}$ Second, my insistence that male and female job categories be equally paid implicitly accepts the validity of commodification of many forms of labor, which feminists have critiqued in other contexts as arising from a phallocentric desire for control. 226 Finally, the model of equality as acceptance also

222. For a critique of meritocracy as a distributive principle, see Wasserstrom, supra note 52, at 619-21.

223. See supra notes $99-103$ and accompanying text.

224. Even access to decisionmaking avoids only some of the problems of "power" as this culture currently understands it. C. GILlIGAN, supra note 11, at 167-68 (on alternative understandings of power); Law in a Different Voice, supra note 131 (remarks of C. Littleton).

225. See B. Babcock, A. Freedman, E. Norton \& S. Ross, Sex Discrimination and the LAw 23-24 (1973) (separate spheres for women and men in social context of inequality allows economic deprivation of women); $c f$. Dalton, supra note 24, at 1110-13 (women unable to recover on implied contract in cohabitation cases because services valued in coin of "love," rather than money).

226. Feminist critique of the commodification of women's bodies and sexuality is common, 
envisions application within, as well as across, spheres of human activity. But from a radical feminist perspective, even that is problematic. For example, a feminist might argue that equalizing across difference only among workers legitimizes the socially constructed division between professional and personal, paid and unpaid, public and private work-a division strongly contested by feminists. 227

Symmetrical equality theorists have argued that because biological sex is no longer a strong predictor of social sex, it is harder to maintain the fiction that biological males are "naturally" better at such things as legal practice. Acceptance goes further, holding that once the social sex of a worker no longer accurately predicts that worker's pay, status, or access to decisionmaking, it will become harder and harder to maintain the fiction that socially male behaviors are "naturally" more valuable than their socially female counterparts. This in turn will make it harder to ignore the value of socially female labor in the "private sphere," while at the same time allowing massive infusion of "private" sphere interests into the "public" arena of employment.

In this respect, then, it does not matter that some elements of the acceptance model reflect the phallocentrism of our culture (as they inevitably must do). If socially male pay scales, status, and access to decisionmaking processes are open, not only to socially male women but also to socially female women and men, women's voice as it is now will be admitted to the dialogue that constructs social meaning. To whatever extent women's voice is not yet authentically our own, the dialogue will still be "tilted," but the frame around it will have moved significantly.

IV

\section{MAKINg Difference Costless}

I have thus far constrained this speculative exercise to respond to equality's legal tradition, ${ }^{228}$ feminist critique of equality, ${ }^{229}$ and feminist critique of male power as a system. ${ }^{230}$ However, I also recognize the

although usually not clearly distinguished from other strands of the critique of pornography-for example, that it may encourage violence against women. See, e.g., Dworkin, supra note 121, at 10 11; Walker, Coming Apart, in TAKE BACK THE NIGHT: WOMEN ON PORNOGRAPHY 84-93, 95-104 (L. Lederer ed. 1982); cf. Radin, Market Inalienability, 100 FARV. L. REV. 1849 (1987) (exploring full and incomplete commodification in several contexts, including surrogate parenting).

227. See, e.g., Olsen, supra note 86, at 1499-1529; Polan, supra note 3, at 298. One aspect of that division is that it does not take into account the unpaid work done outside the workplace by social women. Another is that it does not recognize those aspects of workers identified as "private." More generally, the dichotomy between public and private may distort reality and obscure the historical and context-based relationship among various forms of social relations. See Nicholson, Feminist Theory: The Private and the Public, in BEYond Domination 221-30 (C. Gould ed. 1983).

228. See supra Part I.

229. See supra Part II.

230. See supra Part III. 
need to account for "different kinds of sexual difference."231 Thus, although I do not claim to offer a blueprint for specific application, I will attempt in this Part to lay out the foundation for the house that a reconstructed sexual equality may someday build. ${ }^{232}$

\section{A. Differently Gendered Complements}

The problem of identifying gendered complements lies along two axes of difference. One axis measures the "source" of differences, ranging from the clearly biological to the clearly social (with a great deal of controversy in between). The other measures the degree of overlap between the sexes, and runs from more-or-less differences on one end to yes-or-no differences on the other.

For gender differences that are more-or-less, there is a significant degree of overlap between the sexes. Height is one of these. ${ }^{233}$ Not all women would have been disaffirmed by the too-high podium that was "built for a man,"234 and not all men would have been affirmed by it. But more women than men in this society would have had the feminist lawyer's experience. Additionally, differences of the more-or-less variety are easier to deny, since there is always some woman over six feet or some man under five, and a great number of both in between. These differences are also easier to "match," because shorter and taller are both measures of the same concededly shared human characteristic of height.

For yes-or-no gender differences, there is no overlap at all. The primary example of this is, of course, pregnancy. No man can become pregnant, and most women can. However, women who have never had the capacity for pregnancy are not thereby made either biologically or socially male, even when the dominant culture has tended to view them as "not women." Thus, although it is useful for purposes of analysis to separate yes-or-no differences from more-or-less ones, they represent two poles of the same spectrum.

Disparate treatment analysis under Title VII allows individuals who

231. As I indicated earlier, I believe that this reconstruction of sexual equality may have application to other forms of inequality, see supra note 31 , but the analysis in this Part is limited to differences that have been sexualized- that is, associated with male or female biological or social sex.

232. As many of the examples in this Article demonstrate, equality as acceptance should bc implemented to some extent under current law. In that sense, acceptance is a redefinition of the model used to interpret current law. However, equality as acceptance also suggests particular routes of legislative and cultural change that could be separately explored.

233. Height is a particularly interesting example, because some employment patterns can be predicted just as well by plotting workers' height as by plotting their sex. See B. Kuns, Heightism: Another Barrier 4 (1984) (unpublished manuscript prepared for my course, Women and the Law, UCLA Law School) (on file with the author). Are short men often socially classed as women and devalued on that basis?

234. See supra Part II, section D. 
are exceptions to the "rule" of their biological sex to be socially classed with the other sex. Thus, tall women must be treated the same as tall men, and short men the same as short women. As the podium example demonstrates, phallocentrism in such cases usually involves setting the norm by reference to the center of the male bell curve. When the norm is set by reference to the female bell curve, the same analysis applies; men who can type must be allowed into socially female secretarial positions. ${ }^{235}$

To establish a prima facie case of discrimination under disparate treatment analysis, a plaintiff must show:

(i) that [the plaintiff] belongs to a racial minority [or is a woman]; (ii) that he [or she] applied and was qualified for a job for which the employer was seeking applicants; (iii) that, despite [plaintiff's] qualifications, he [or she] was rejected; and (iv) that, after [plaintiff's] rejection, the position remained open and the employer continued to seek applicants from persons of complainant's qualifications. ${ }^{236}$

Requiring a female complainant to establish "qualifications" for a traditionally male job is to require her to establish that she is socially male, at least in this context.

Disparate impact analysis, on the other hand, allows socially female women to bring equality claims if the job qualification containing the gendered norm is irrelevant to the applicant's ability to perform the job. No showing of direct intent to discriminate is required. ${ }^{237}$ Under disparate impact doctrine, then, a woman can establish discrimination by demonstrating that women as a class are more severely affected than men by a facially neutral employment practice, such as a height requirement. $^{238}$ The employer can, however, justify the discriminatory impact by demonstrating that the practice is "job related" or necessary to the employer's business. ${ }^{239}$ Moreover, the relevance of the practice is tested solely by reference to the way the job is already structured. ${ }^{240}$ Thus,

235. It appears that the advent of computers may have shifted the male curve of typing ability.

236. McDonnell-Douglas Corp. v. Green, 411 U.S. 792, 802 (1973). The disparate treatment criteria are exactly the same for race or sex, see Texas Dept. of Community Affairs v. Burdine, 450 U.S. 248 (1981) (sex discrimination claim based on disparate treatment), and are intended to be applied flexibly, so as to serve the same purposes in different contexts. Id. at 253-54 n.6. Thus, in claims of disparate treatment in promotion, the criterion of "the job remained open" is replaced by "the job was flled by a person of the other sex."

237. Griggs v. Duke Power Co., 401 U.S. 424 (1971).

238. The Court has stated that Title VII protects whites just as it protects non-whites, and men just as it protects women. See, e.g., Newport News Shipbldg. \& Dry Dock Co. v. EEOC, 462 U.S. 669 (1983); Regents of the Univ. of Calif. v. Bakke, 438 U.S. 265, 308-09 n.44 (1978). While disparate impact analysis should, therefore, theoretically be equally available to male plaintiffs, I am aware of no sex discrimination cases in which men have asserted this theory. This could indicate that work rules that select for women tend to be more job-related than work rules that select for men, or that men are perfectly happy not to be classed as socially female.

239. Griggs, 401 U.S. at $429,431$.

240. A court might question an employer's post hoc characterization of a job, see Diaz v. Pan 
even disparate impact analysis-as currently practiced-does not allow for challenges to male bias in the structure of businesses, occupations, or jobs. ${ }^{241}$

Equality as acceptance would support challenges to government and employer policies and practices that use male norms even when such norms are considered job-related, necessary to the business, or "substantially related to an important governmental interest." 242 Unlike the more radical version of the model of androgyny referred to above, ${ }^{243}$ however, acceptance would not necessarily require the elimination of such norms. Acceptance could instead be achieved by inventing complementary structures containing female norms. For example, assume an employer successfully defends its 5' ' minimum height requirement as necessary to the job of sorting widgets as they pass on a conveyor belt. Equality as acceptance could be achieved by restructuring the job itself-in this case, by changing the height of the conveyor belt or by adding a second belt. Alternatively, the employer could defend the requirement by demonstrating that equal job opportunities exist in the plant for applicants shorter than 5'9". Acceptance would thus permit de facto sex segregation in the workplace, but only if the predominantly male and predominantly female jobs have equal pay, status, and opportunity for promotion into decisionmaking positions. ${ }^{244}$

Yes-or-no differences do not yield so readily to matching. This has helped focus the "equal treatment/special treatment" debate on pregnancy-specifically, on the question of whether requiring employers to grant pregnancy leaves for women violates the equal rights of men, who can never take advantage of such leaves. ${ }^{245}$ If pregnancy were a more-orless difference, such as disabling heart trouble or childcare responsibility, it would be easy for the current legal system to answer this question. Since it is a yes-or-no difference, however, the legal system runs in circles: the Supreme Court in Geduldig v. Aiello ${ }^{246}$ said pregnancy is different, so women can be punished for it; the federal district court in Cal. Fed. ${ }^{247}$ said pregnancy is not different, so women should not benefit from

Am. World Airways, Inc., 442 F.2d 385 (5th Cir.) (finding the purpose of the airline business to be safe transportation, not comforting passengers), cert. denied, 404 U.S. 950 (1971), but it will still evaluate the business as it is, not as it might be if it were not male-biased.

241. This does not mean that Title VII could not be interpreted to allow such challenges, only that its current interpretation does not, Wendy Williams' optimistic reading to the contrary. Sec Williams, Equality's Riddle, supra note 2, at 331 (disparate impact analysis is a doctrinal tool useful for "squeez[ing] the male tilt out of a purportedly neutral legal structurc").

242. See supra note 21 .

243. See supra notes $82-86$ and accompanying text.

244. This example demonstrates the ease with which equality as acceptance would embrace claims of "equal pay for comparable work." See supra text accompanying notes 172-75.

245. See supra notes 111-14.

246. 417 U.S. 484 (1974).

247. California Fed. Sav. \& Loan Ass'n v. Guerra, 33 Empl. Prac. Dec. (CCH) 丹 34,227 (1984), 
it; the Supreme Court, affirming the Ninth Circuit in Cal. Fed. ${ }^{248}$ said pregnancy is different, so men are not hurt by taking account of it.

I think that the appropriate unit of analysis in yes-or-no cases is interaction of the sexes rather than comparison. Even with rapidly developing reproductive technology, it is still necessary for some part of a woman to interact with some part of a man to produce a pregnancy. In that interaction, the gendered complements are pregnancy for the woman and fewer sperm cells for the man. Since pregnancy almost always results in some period of disability for the woman, making the sex difference costless with respect to the workplace requires that money, status, and opportunity for advancement flow equally to the wombdonating woman and the sperm-donating man (himself an equal contributor to the procreative act). ${ }^{249}$

Both average height and pregnancy lie near the biological pole of the source axis; these differences are clearly biological. Their existence and degree of overlap are less problematic as an empirical matter than differences lying closer to the cultural pole. ${ }^{250}$ The clearly cultural differences, on the other hand, are more problematic, primarily because they are even more likely than biological differences to give rise to stereotypes that harm women. ${ }^{251}$ Arguments for ignoring difference are also more plausible with reference to the cultural axis. Because these differences are acquired, they can presumably be done away with, if not for us then for our children or grandchildren. ${ }^{252}$ This combination of danger and plau-

rev'd 758 F.2d 390 (9th Cir. 1985), aff'd, 107 S. Ct. 683 (1987); see supra text accompanying notes 104-15.

248. 107 S. Ct. 683 (1987).

249. Equality as acceptance does not itself dictate whether this acceptance should be accomplished by (1) female and male workers sharing the disadvantage that the workplace now visits on women alone--perhaps through requiring male employees to take on without extra pay some portion of the work of the absent female employees; (2) eliminating the disadvantage to women through some form of pregnancy leave rights; or (3) reshaping the structure itself so that no disadvantage arises at all-through more radical time-shifting, time-sharing work schedules or through elimination of the workplace-home dichotomy. While equality as acceptance would support arguments for all three, option (2) is probably the most viable currently.

250. But see Note, supra note 26 , at $497-98$ (suggesting the biological-cultural distinction is itself cultural).

251. See Taub, supra note 190 , at $349-61$.

252. Why bother with making these differences costless relative to each other if we can get rid of them altogether? My response is similar to that given to androgyny as an equality model: getting rid of difference in a system of male dominance means getting rid of women's differences. For example, "equality" in private law firm practice seems to mean that both women and men who take parenting leave fail to make partner; "equality" in academia seems to mean that both women and men whose research field is women's studies are not considered "serious" scholars. Cf. Lynn v. Regents of the Univ. of Calif., 656 F.2d 1337 (9th Cir. 1981) (university's disdain for women's studies is evidence of sex discrimination), cert. denied, 459 U.S. 823 (1982). Similarly, my female students are consistently counseled to wear gray or navy blue "power suits" to job interviews (often with little string or silk "ties").

Until such time as "getting rid of sex differences" has some chance of operating equally, it is an 
sibility has led several sex equality theorists to place themselves toward the middle of the symmetrical vs. asymmetrical debate. ${ }^{253} \mathrm{I}$ am, however, either brave or foolhardy enough to believe that even cultural differences can be made accessible to equality analysis.

Cultural differences of the more-or-less variety can be dealt with along the saine general lines as biological differences that overlap. Under acceptance, inarital dissolution decrees, for example, could value the contributions of the non-earner spouse (usually, but not always, the woman), take into account services in the home performed after divorce, and treat realistically the expenses necessarily incurred by the custodial parent. These ineasures would go further toward reducing the potentially devastating econounic impact of divorce for women than current experiments, such as presuinptions in favor of joint custody. ${ }^{254}$

Cultural differences of the yes-or-no variety are easier to identify than those of the more-or-less, but harder to deal with. Fortunately, there are relatively few of thein (far fewer than there were a few decades ago). ${ }^{255}$ The most visible is einployment in the armed services. Women are excluded from draft registration, and female volunteers are excluded froin coinbat positions. ${ }^{256}$

empty (perhaps deadening) promise for women. Moreover, it does not seem particularly unfair for women to demand a little equality now, for ourselves, without waiting for our grandchildren to "grow up free." Nor does it seem unjustified for women to be accepted as equal members of this society in spite of our cultural skewing-after all, men are skewed too, albeit differently. Of course, there is the obligatory fallback position that the opportunity for "social transvestitism" I envision as a result of this strategy will actually hasten the day that sex differences cease to operate for most people. However, societies are not built by or for people who may never exist, nor even for the purpose of creating such people.

253. See, e.g., Kay, supra note 97 ; Law, supra note 96 (both advocating a symmetrical model as the norm, with some area of asymmetry).

254. Cf. Bartlett \& Stack, Joint Custody, Feminism and the Dependency Dilemma, 2 Berkeley WOMEN'S L.J. 9 (1986).

255. Compare, e.g., Bradwell v. Illinois, 83 U.S. (16 Wall.) 130, 140.42 (1873) (Bradley, J. concurring) (women are naturally unfit to practice law) with Hishon v. King \& Spalding, 467 U.S. 69 (1984) (partnership decisions in law firm must be made without regard to prospective partner's sex).

256. Feminists are as deeply divided in their responses to this issue as they are with regard to separate pregnancy leave. On the one hand, the current institution of combat is the apotheosis of phallocentrism, a nonstop program of hierarchy, barely controlled aggression, and alienation. $C$. ENLOE, Does KHAKI BeCOME You? 12-15 (1983) ("To be prepared for combat, to soldier, a man must be stripped of all his 'feminine' attributes."). Perhaps we should be grateful to be excluded and spend our energy working to get the men excluded, too. On the other hand, it is combat experienee that sends soldiers up the military promotion ladder, see Schlesinger v. Ballard, 419 U.S. 498 (1975), increases their pay and benefits, and apparently fits them for high public office. Wendy Williains phrases it as the "I want what he's got but I don't want to be what he's had to be to get it" syndrome. Williams, The Equality Crisis, supra note 27, at 189.

Are women reluctant to engage in defense, or are they merely reluctant to engage in the glorification of brutality and apparent hysteria that combat training seemingly entails? 1 agree with Dru Cornell's prediction that if it were not so expensive for men to opt out of this particular warrior role, more of them would do so. D. Cornell, supra note 99, at 72 . If fewer men were willing to engage in the warrior role, we as a society might be forced, in order to attract enough men and 
Just as gendered complements in the "biological" realm come from our current perceptions of biology, so must gendered complements in the "cultural" realm come from our current perceptions of culture. The traditional gender divide sets up "warrior" in its cultural sense directly opposite "mother" in its cultural sense. ${ }^{257}$ The "cult of motherhood"258 resembles the "glory of battle" in a number of ways. ${ }^{259}$ Both occupations involve a lot of unpleasant work, along with a real sense of commitment to a cause beyond oneself that is culturally gussied up and glamorized culturally to cover up the unpleasantness involved. Both involve danger and possible death. And, of course, the rationale most frequently given for women's exclusion from combat is their capacity for motherhood. ${ }^{260}$

Making this gender difference less costly could mean requiring the government to pay mothers the same low wages and generous benefits as

women, to experiment with different visions of the role-to move from warrior to defender, for example.

257. Williams, The Equality Crisis, supra note 27, at 190.

258. Glorification of motherhood and a concomitant preoccupation with it are, of course, cultural artifacts, with only a tenuous connection to biological factors. For a cultural materialist examination of how and why the cultural meaning of motherhood changes over time, see $M$. Margolis, Mothers AND Such 1-107 (1984).

259. I am grateful to both Sheila McIntyre and Michael Schiff for pointing out that equating cultural motherhood and cultural soldierhood could easily be viewed as undervaluing motherhood. The potential for disagreement over which gender roles are complements demonstrates the necessity for a research agenda as well as public debate that will elucidate the ways in which American culture sexualizes difference. In the meantime, I have debated the wisdom of continuing the parallel and have decided to do so for the following reasons.

First, a competing parallel might be drawn between defense and maintenance-i.e., between soldiers and domestic workers (paid and unpaid). This parallel would draw on a schema that divides the activity of a society into four quadrants: production, reproduction, defense and maintenance. I have already drawn a parallel between production and reproduction, see supra note 249 and accompanying text, and it might thus be fitting to draw a parallel here between defense and maintenance. The only reasoll not to do so is that the mother/soldier parallel has been drawn often before, both informally and formally. See, e.g., Williams, The Equality Crisis, supra note 27, at 179, 190.

Second, the possible undervaluation of motherhood entailed by the mother/soldier parallel is similar to the possible undervaluation of women's work implied by the elementary school teacher/ garbage collector or nurse/real estate appraiser parallels so familiar to comparable worth discussions. See, e.g., Lemons v. City and County of Denver, 17 Fair Empl. Prac. Cas. (BNA) 906 (D. Colo. 1978) (denying comparable worth claim made by nurses). Undervaluing the traditionally female half of the parallel is only additional evidence of the culture's phallocentrism; it does not justify refusing to revalue nurses, teachers, and mothers at least to the extent that real estate appraisers, garbage collectors, and soldiers are valued.

Finally, I do not intend the specific complements I suggest in this Article to do anything more than open systematic inquiry into, and debate about, how equality could be achieved across difference. I frankly lack the cultural anthropology background to do any more. But I encourage interdisciplinary inquiry leading to a more sophisticated understanding of how our culture creates and hierarchizes gendered complements. See also infra note 263.

260. See, e.g., S. REP. No. 826, 96th Cong., 2d Sess. 159, 161, reprinted in 1980 U.S. CODE Cong. \& AdMIN. News 2612, 2649-51. But see C. ENLOE, supra note 256, at 15 (women in combat would confuse men's certainty about their male identity). 
most soldiers. ${ }^{261}$ It could also mean encouraging the use of motherhood as an unofficial prerequisite for governmental office. ${ }^{262}$ As a paying occupation with continuing status perks, many more men might be induced to stay home and raise their children. ${ }^{263}$ Alternatively, but less likely, making difference costless could mean ceasing to pay combat troops.

For example, in Personnel Administrator v. Feeney, ${ }^{264}$ the Supreme Court upheld Massachusetts' lifetime veteran's preference against an equal protection challenge, reasoning that Massachusetts had not intended that preference to lock women into lower-level and dead-end civil service positions, regardless of this obvious effect. Under an equality as acceptance model, a state's failure to provide equal preference for the gendered female complement to military service would be evidence of intentional discrimination. Thus, even without additional constitutional or statutory enactment, a change in the Court's underlying model of equality could alter the result in actual cases. ${ }^{265}$

Matching gendered complements in order to equalize across cultural differences may sound like marching directly into the valley of the stereo-

261. Aid to Families with Dependent Children (AFDC) programs might be the culture's partial recognition of the importance of the occupation of childcare. However, that AFDC payments arc seen as a response to need, rather than an earned income, makes them vulnerable to political windshifting. On the relative weakness of claims based on need, as opposed to claims based on rights, sec Littleton, Equality Across Difference, supra note 37. In addition, social labelling of AFDC payments as "charity" rather than earnings has a necessary impact on recipients' self-imagc and sense of worth. Altering the basis and measurement of AFDC payments by making them the equivalent of military pay could go a long way toward alleviating both the feminization of poverty and the negative impact of social welfare programs on the purported beneficiaries. Additionally, the educational programs available in the military and by virtue of financial assistance following military service are far superior to the paltry "job training" programs currently available to welfarc recipients.

262. Establishing motherhood as an unofficial prerequisite for governmental office could be accomplished largely through changes in media treatment of female political candidates and by establishing preferences for employment similar to those granted veterans. See supra text accompanying notes 195-97. Granting veterans' preferences for state civil service jobs sends a strong message that military service is valued (as past services rendered) and valuable (as job training). With relative ease, a state could send a similar message with respect to primary parental responsibility. See infra text accompanying note 264 . Finally, federal law requires that employees absent from work due to military training or service be reinstated on their return. Why are similar job guarantees for employees absent due to childbearing a matter of state choice? Compare California Fed. Sav. \& Loan Ass'n v. Guerra, 107 S. Ct. 683 (1987) with Wimberly v. Labor \& Indus. Relations Comm'n, $107 \mathrm{~S}$. Ct. 821 (1987) (states may, but need not, take account of pregnancy in order to ensure actual equality between working women and men).

263. Although it is readily apparent that men can also "mother," motherhood as a cultural construct is bound up with motherhood as biological condition. This slippage along the source axis is intriguing. If there is any biological component to the social category of "mother"-i.e., a component not contained in the category of "primary parent"-it may eventually be eliminated through advances in reproductive technology.

264. 442 U.S. 256 (1979).

265. The exact parameters of a complementary preference system sufficient to withstand equal protection scrutiny might not, of course, be litigated in the initial action, but that is hardly unique to this model of equality analysis. 
types. Those who consider Carol Gilligan's discovery of "a different voice" sexist are not likely to find this appealing. Nevertheless, allow me to make two disclaimers. First, almost all cultural differences are, or could easily be, "more or less." Lots of biological men exhibit socially female characteristics (for which they are all too often punished); at least as many biological women exhibit socially male ones (for which they are often rewarded, although they are simultaneously punished for not having the biological form to match); ${ }^{266}$ and many more women and men fall in the middle, exhibiting no readily identifiable "male" or "female" behavior patterns. Second, what is objectionable about stereotypes is not that they are never true, but rather that they are not always true. Demonstrating that not every woman with children is primarily responsible for their care may help those women who do not have such responsibility to compete for certain jobs, but it does little to help those women struggling to hold down two jobs, only one of which is paid.

Disclaimers aside, what is relevant for this exercise is not the accuracy or inaccuracy of any set of gendered complements, but rather how the complements reward or punish those who are perceived to fall on one side or the other. Studies of sex-segregated work places tend to show that there is a high correlation between employer perceptions of gender differences and the segregation patterns themselves. ${ }^{267}$ These perceived gender differences, such as lifting strength and small-muscle dexterity, are of the more-or-less type, and tend to fall toward the middle of the "source" axis. ${ }^{268}$ Requiring individual testing alleviates segregation to some extent, but it only helps those women who do not fit the female stereotype (at the expense, of course, of those men who do not fit the male stereotype). However, the main problem with sex segregation is that promotion patterns and pay scales are determined by entry-level job classifications. Thus, those women who do fit the female stereotype (of, say, low lifting strength and high small-muscle dexterity) are stuck. They are not harmed by the "female" job classification as such; they are harmed by the disparity in pay and opportunity for promotion that goes along with it. And the disparity in promotion opportunities continues the cycle of overvaluation of "male" characteristics and undervaluation of "female" ones, because employers will continue to select those biological men and women who are socially male.

If, alternatively, both "male" and "female" entry-level positions

266. See, e.g., supra notes $159-63$ and accompanying text.

267. See W. Biebly \& J. Baron, Men and Women at Work: Sex Segregation and Statistical Discrimination 27-28 (1985) (unpublished manuscript on file with the author) ("In short, the statistical results suggest that employers do reserve some jobs for men and others for women, based on their knowledge of technical and organizational features of work and their perceptions (however accurate) of sex differences in skills and work orientations.").

268. Id. at 22-33. 
paid the same and offered the same promotion opportunities, individual testing would not matter so much. Indeed, assuming proportionate numbers of openings, applicants might well self-select into the classification that better utilizes their particular strengths and minimizes their particular weaknesses. If so, the segregation pattern would gradually break down unless employers actively and, legally speaking, "intentionally" sought to maintain it. Moreover, even if self-selection by individual skills did not occur, a better sex mix at the management level would eventually have a significant impact throughout the firm.

As Frances Olsen sets forth in The Sex of Law, we tend to think in dichotomies, and those dichotomies are both sexualized (with one side masculine and the other feminine) and hierarchicized (with one side in each pair superior). ${ }^{269}$ She argues that the sexualization and hierarchicization should be attacked simultaneously, to the end of deconstructimg the dichotomies themselves. While I do not disagree with this goal, I do think Olsen's strategy is impractical. Dichotomies that purport to describe gender differences are, I think, only likely to fall apart once they no longer accurately describe differences in pay scales, hiring patterns, or promotion ladders. Additionally, since we presently think in these dichotomies, we may as well use them to help us in our struggle to discard them.

The rigidity of sexualized dichotomies does appear to be gradually breaking down in many areas. Whether the strategy I am suggesting would impede that breakdown is discussed below. With regard to the practical problem of implementation, however, the true breakdown of any particular male-female dichotomy is not a problem, but a benefit. It puts us one step closer toward eliminating them entirely.

\section{B. Reifying Gender}

The theoretical problem of the above discussion is, of course, the danger that using gendered complements overtly (I remain convinced that we use them covertly all the time) will strengthen the gender divide. This danger seems real, although perhaps overstated if the rest of my analysis holds. As I have urged throughout this Article, it is not gender difference, but the difference gender makes, that creates a divide. Instead of division, there might easily be a continuum stretching beyond the current poles-the "polymorphous perversity" that Jeff Goldstein posits in the erotic arena ${ }^{270}$ or the "reds and greens and blues" that Frances Olsen imagines within a liberated androgyny. ${ }^{271}$ If the status of "victim" were not so debilitating in socially real terms, we would be able to laugh at the

269. Olsen, supra note 40 , at $1-4$.

270. Goldstein, Pornography and Its Discontents, Village Voice, Oct. 16, 1984, at 19, 44.

271. Olsen, supra note 86 , at 1578 . Olsen describes androgyny as arising from the synergism of 
argument that the Minneapolis antipornography ordinance ${ }^{272}$ paints women as victims of male violence. ${ }^{273}$ Similarly, if the location of a person, action, or characteristic on the "female" side of the divide did not entail her/his/its immediate devaluation, then the mere identification of a law's beneficiaries as "women" would not divert us from a deeper and more practical analysis of its relative advantages and disadvantages.

There is yet another layer, however, to the critique of reifying gender. Not only is the socially female a constructed category, but that social construction was historically created in the absence of women, or at least without their participation. Therefore, runs the criticism, the socially female cannot be claimed as truly belonging to women, because it has been men who have done the defiming. How, then, can I claim it as valuable on behalf of women? ${ }^{274}$

I am not claiming that women's authentic voice would value everything that has been assigned to us by social definition. I literally do not know what I would say about my selfhood had I not been raised in a phallocentric culture - and neither does anyone else. However, as long as identification with socially female attributes is more "expensive" than identification with socially male ones-when taking parental leave shunts you off the partnership track, crymg in a meeting shuts off the discussion, breastfeeding makes you unacceptable at the restaurant table-we are not ever going to be in a position to find out what women would value for themselves. ${ }^{275}$

The social construction of "woman" has not just been a matter of men taking the best for themselves and assigning the rest to women. It has also been a matter of perceivmg the "worst" as being whatever women were perceived to be. ${ }^{276}$ This interaction can be disrupted either

male and female, rather than their union, and thus yielding characteristics not otherwise displayed by either. How this process is to take place is not explained.

272. See supra note 121 .

273. See, e.g., Vance, Pleasure and Danger: Toward a Politics of Sexuality, in Pleasure AND DANGER: EXPLORING FEMINIST SEXUALity 7 (C. Vance ed. 1984) ("If women increasingly view themselves entirely as victims through the lens of the oppressor and allow themselves to be viewed that way by others, they become enfeebled and miserable.").

274. See Feminist Discourse, supra note 13, at 74-75 (MacKinnon objecting to calling the voice of powerlessness women's voice).

275. I understand Catharine MacKinnon to be making a similar epistemological point, but basing it on inequality of power rather than inequality of social value. See, e.g., MacKinnon, Toward Feminist Jurisprudence, supra note 117, at 635-36. To the extent that social value is a manifestation of power, she might validly criticize equality as acceptance for being aimed at symptoms rather than causes. To the extent that social value creates power, I might respond in kind. To the extent that social value and power create each other, we might simply say that we choose different points of attack.

276. Does the Dictionary of Occupation Titles rate childcare as unskilled work because it "really" is, or only because those speaking in the public discourse never saw or formalized the instruction that took place every day that we watched our mothers or cared for younger children ourselves? See Briggs, Guess Who Has the Most Complex Job?, reprinted in B. BABCock, A. 
by revaluing what women have been perceived to be, or by reassigning the attributes that comprise the social sexes, or both. ${ }^{277}$ However, I am making a claim for one form of disruption rather than the other, based on my analysis of male power as a system, presented in Part III. So long as equality analysis takes place in a system defined by the club, reassignment of social sex attributes must itself operate unequally. My claim is also based on the quasi-empirical observation that women are willing to pay an increasingly heavy price to maintain at least some socially female modes of being, ${ }^{278}$ and that men are unwilling, or unasked, to pay a similar price to take them on. To take one example, reassigning childcare has not thus far meant assigning it to men or even sharing it with them; it has meant assigning it to poorer women. Despite a rapid increase in the number of married women in the full-time labor force, men's contributions to household tasks have remained astonishingly low. ${ }^{279}$ For the sexual dialectic to yield anything transformative, we have got to take our social finger off one end of the scale.

As indicated above, making gender difference costless, even in the skewed terms by which we now measure "cost," seems just as likely to decrease the overlap between biological and social sex as ignoring what we perceive as gender difference in the hope that it will disappear or be "transformed." If it costs most men and women the same to stay home with the baby, parenting is more likely to be shared. (Currently, women have less to lose than men by foregoing paid employment for unpaid childcare, since both women's salaries and expectations are generally lower.) And if the social rewards of childrearing are closer to those of what we now think of as employment, making the two compatible can proceed from two directions instead of one. ${ }^{280}$

It is, of course, possible that "social transvestitism" will not occur to any great extent, even if it becomes relatively costless. Perhaps biological or cultural imperatives do play a larger role than power and economics. I doubt it. ${ }^{281}$ But if it does turn out that, given a flat cost curve, most

FreEdman, E. NoRTon \& S. RosS, supra note 225 , at 203 . If the reply is that childcare is "instinctual," then so is tool-use, but neither point is relevant. Modern human childrearing is as different from instinctual parental behavior as modern human tool use is different from its instinctual counterpart.

277. See Olsen, supra note 40.

278. See, e.g., J. Foster, Antigones at the Bar: Women Lawyers as Reluctant Advcrsaries (1984) (unpublished manuscript on file with the author).

279. P. ROOS, GENDER \& WORK 13-19 (1985).

280. Also, acceptance may encourage development of not just combinations of socially male and female, but also new modes of existence that are not cxhausted by the catalog of shared attributes. Only in an equal dialectic between male and female are such new modes likely to arise. For example, interdependence of the sexes cannot be realized until independence accepts dependence as an "equal bargaining partner." And interdependence is not simply both parties being a little dependent and a little independent, nor is it taking turns being both. It is a "horse of a different color" altogether.

281. Wendy Williams notes, in her discussion of Sweden's government-sponsored, paid 
biological women opt for social womanhood and most biological men opt for social manhood and very few explore new modes of social existence, I'm not sure I'd care very much. The modernists may enjoy mixing things up for its own sake; me, I'm only in it for the equality.

\section{The Project That Remains}

Three major lines of further inquiry and analysis remain largely unexplored, although the problems created by their absence have been alluded to throughout this part. ${ }^{282}$ They ask the questions: (1) what differences exist? (2) how are they created and maintained? and (3) what cultural meanings do they embody?

A body of scholarship already exists on the first question, and legal scholars are beginning both to make use of and add to that body. ${ }^{283}$ However, especially in legal scholarship, the explorations thus far have been tentative and speculative, when not conclusory or rash. While caution is certainly appropriate in this venture, what is needed now is more empirical sociological data.

The second line of inquiry asks how difference interacts with power imbalances between the sexes. Sometimes it is possible, even under conditions of inequality, to see the way power imbalances have cross-cut difference, twisting it into an unlovely shape. ${ }^{284}$ For example, Carol Gilligan's work has stimulated countless conversations about the "ethic of care" associated with women. Gilligan certainly meant to revalue caring for others as a moral orientation. However, when your existence depends on the sufferance of those others, such an orientation can be twisted into a kind of "pleasing" that has everything to do with satisfying surface whims and little to do with affirming the others' selfhood. ${ }^{285} \mathrm{~A}$ model of acceptance would require that caring and pleasing be valued as are their respective gendered complements. Thus, tentatively, caring and self-reliance would be valued equally, and pleasing in its twisted form would only be valued as much as the twisted form of self-reliance, that obliviousness to others that arises from their dependence on your sufferance.

The third line of inquiry explores the cultural meanings of differ-

parenting leave program, that initially many more women than men took advantage of the program, but that men's participation is constantly increasing. Williams, Equality's Riddle, supra note 2, at 378.

282. See supra notes $252 \& 259$.

283. See, e.g., Menkel-Meadow, supra note 13 (exploring the impact of women lawyers upon the practice of law); Karst, Woman's Constitution, 1984 DUKE L.J. 447 (exploring how women's values might inform traditional liberal interpretations of constitutional law).

284. Regardless whether difference would exist in some essentialist form outside the power imbalance, it is nevertheless the case that some twists are within the range of our current vision.

285. See Feminist Discourse, supra note 13, at 25 (women have had little choice over the things for which they are valued). 
ence. Charles Lawrence has pointed out the ways in which the failure to take account of cultural meanings perpetuates the effects of unconscious racism and insulates this form of inequality from legal redress. ${ }^{286}$ Perhaps lawyers, too, could benefit from engaging in a form of cultural anthropology, trying to uncover the cultural meanings of gender differences that hide behind the guise of nature. ${ }^{287}$

Many questions remain unanswered. Are there differences that perpetuate phallocentrism by their mere existence? If so, how are they to be identified? Laid out in this fashion, the research agenda appears daunting. However, much of this appearance is engendered by legal academia's relative ignorance of other disciplines. The emphasis of feminist jurisprudence on interdisciplinary study should provide a long-overdue corrective for this. ${ }^{288}$ We need to engage in more sophisticated inquiry into gender difference, and a model of equality as acceptance facilitates, but does not accomplish, that inquiry.

Equality as acceptance provides a methodology for assuring that sexual differences do not take on the unnecessary consequence of sexual inequality. In order to apply that methodology, we must open inquiry into the identification, use, and meaning of such differences. Through a model of equal acceptance, the legal system, which has historically been a conduit through which perceived difference between both sexes has rationalized concrete disadvantage to one, may finally become an arena for reclaiming equality across difference.

\section{CONCLUSION}

In this Article, I have outlined the model of equality as acceptance. The claims I have made for this model are both modest and immodest: modest, in that I do not claim that even full implementation would automatically result in full sexual equality; immodest, in that I claim that even partial implementation would allow both theorists and policymakers to see new ground for equality that is obscured now. Acceptance would, at the very least, loosen the grip that hierarchical ordering by sex has kept on our lives and on our imaginations.

As I look back on the argument made here on behalf of the model of acceptance, I perceive these major points: (1) in order to be faithful to feminist critique, a reconstructed equality norm must be capable of application across or beyond difference; (2) although no reconstruction under-

286. Lawrence, supra note 178, at 355-62.

287. My colleague at Loyola Law School, Sheila Kuehl, has suggested to me that women might discover more about sex and sexism by taking on the role of "Martian anthropologists."

288. See H. Kay \& C. Littleton, Introduction to Feminist Jurisprudence, address delivered at American Association of Law Schools mini-workshop on Emerging Legal Traditions, Los Angeles (Jan. 3, 1987). 
taken under conditions of inequality can claim to be completely free from phallocentric bias, a reconstruction can increase equality and invite later, freer reconstructions by shifting the frame and moving the margin into the picture; (3) making difference costless (or even cost less) will shift the frame, allowing us to see ever more subtle forms of phallocentric bias while reducing the danger that difference will be used to re-create inequality; (4) the model of costless difference can be applied within contexts without impeding later efforts to apply it across contexts; and (5) much of the model's usefulness can be realized now, without waiting for major legislative or cultural change. ${ }^{289}$

The enormity of the project that remains, however, should not be underestimated. We know very little about difference in its liberatory potential, and much about its potential to divide and oppress. However, if the answers we discover about difference can increase equality rather than decrease it, I am confident we will find them.

289. I recognize the significant strain of optimism that runs through this Article. At a time when the incredible pain and suffering of women is only beginning to be uncovered, it is hard to be optimistic. I acknowledge that much of my optimism arises from the very privileged place I have occupied at various times in my life. But my faith in the possibility of equality encompassing difference is based on experience. I was fortunate enough to have a mother who believed her four very different children should be equals. She did not always succeed in making our differences costless, but she did enough to give me a taste of what acceptance can mean. I now want the same for all of us. 
